

\section{Sumário}

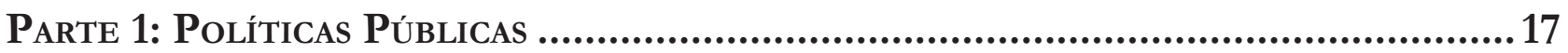

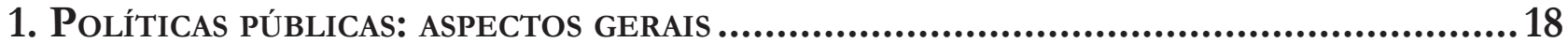

UM MODELO POLÍTICO DE IMPLEMENTAÇÃO PARA AS POLÍTICAS PÚBLICAS: OS PAPÉIS DO DIREITO E DOS JURISTAS.

William H. Clune III

Evaluación de las obras públicas en gobiernos locales en MÉxico: Desafíos de LaS POLÍTICAS PÚBLICAS DE PARTICIPACIÓN CIUDADANA

Louis Valentin Mballa e Arturo Bermúdez Lara

Paternalismo libertário e políticas públicas: intervenção e transparênCia

Marcia Carla Pereira Ribeiro e Victor Hugo Domingues

2. Políticas públicas E COVID-19

LiMITES E POSSIBILIDADES PARA O USO SECUNDÁRIO DE DADOS PESSOAIS NO PODER PÚBLICO: LIÇÕES DA PANDEMIA.

Miriam Wimmer

EFICIÊNCIA DAS POLÍTICAS DE INOVAÇÃO NOS SETORES INDUSTRIAIS BRASILEIROS: SUGESTÕES PARA A CRISE DA COVID-19

Michelle Márcia Viana Martins e Chrystian Soares Mendes

CoMPLIANCE EM TEMPOS DE CALAMIDADE PÚbLICA: ANÁLISE SOBRE A FLEXIBILIZAÇÃo DA TRANSPARÊNCIA DE DADOS E INFORMAÇÕES DURANTE O ENFRENTAMENTO DA COVID-19 NO BrasiL

Luciana Cristina da Conceição Lima, Alcindo Fernandes Gonçalves, Fernando Cardoso Fernandes Rei e Cláudio Benevenuto de Campos Lima

3. Políticas públicas e accountability

ACCOUNTABility E DESENHO INSTITUCIONAL: UM “PONTO CEGO" NO DIREITO PÚBLICO BRASILEIRO

Danielle Hanna Rached

ESTRATÉGIAS REGULATÓRIAS DE COMBATE À CORRUPÇÃo 
O controle e a avaliação pelo Tribunal de Contas da União das políticas públicas IMPLEMENTADAS POR DESONERAÇÕES TRIBUTÁRIAS NO BRASIL

Vinicius Garcia e Carlos Araújo Leonetti

4. Políticas públicas em Matéria de SAÚde

A livre opÇão pela Cesariana: um "NUdge Às aVessas". .268

Bruna Menezes Gomes da Silva e Júlio Cesar de Aguiar

AUTISMO: ASPECTOS JURÍDICOS DA ACESSIBILIDADE E RESPEITO

Fabiana Barrocas Alves Farah e Danilo Fontenele Sampaio Cunha

SAÚdE E DOENÇAS RARAS: ANÁLISE DA JUDICIALIZAÇÃo DO ACESSO AO TRATAMENTO E SUAS LIMITAÇÕES.

Danilo Henrique Nunes e Lucas de Souza Lehfeld

5. OUTRAS POLÍTICAS PÚBLICAS EM ESPÉCIE

REGUlAÇÃO DAS ÁGUAS: UMA ANÁLISE EMPÍRICA DA PRODUÇÃo NORMATIVA DOS ÓRGÃOS REGULADORES FEDERAIS

Bianca Borges Medeiros Pavão, Natasha Schmitt Caccia Salinas e Thauany do Nascimento Vigar

“LET THE ALGORITHM DECIDE": IS HUMAN DIGNITY AT STAKE?.

Marcela Mattiuzzo

DAS ACEPÇÕES DOS DIREITOS DOS REFUGIADOS ÀS VOZES SILENCIADAS NAS POLÍTICAS PÚBLICAs371 Thaís Araújo Dias e Monica Mota Tassigny

Planejamento familiar: “inimigo" a Ser combatido, “aliado” libertador ou falso "AMIGO"?

Vinicius Ferreira Baptista

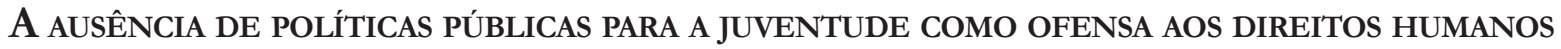
William Timóteo e llzver de Matos Oliveira

AnÁlise CÊniCa dos feminicídios em Curitiba: propostas preventivas e repressivas ....433 Ticiane Louise Santana Pereira, Octahydes Ballan Junior e Antonio Henrique Graciano Suxberger

ORIGIN AND CONSEQUENCES OF THE WAR ON DRUGS. FROM THE UNITED STATES TO ANDEAN COUNTRIES

Silvio Cuneo e Nicolás Oxman 
Trabalho Decente: comportamento Ético, política pública ou Bem JuRIDiCamente TUTELADO?.

Silvio Beltramelli Neto e Mônica Nogueira Rodrigues

El FINAL DE UNA POLÍtica PÚBLICA: ANÁLISIS DEL CICLO POLÍTICO DEL PROYECTO DESTINOS INDUCTORES PARA EL DESARROLLO TURISTICO REGIONAL (DIDTR) - BRASIL. .496

María Belén Zambrano Pontón, Magnus Luiz Emmendoerfer e Suely de Fátima Ramos Silveira

Alternativa tecnológica para COMPensaÇão de CRÉditos de ICMS: ESTUdo de Caso da VIABILIDADE DO USO DE DLT EM NOTA FISCAL ELETRÔNICA .520

Danielle Mendes Thame Denny, Roberto Ferreira Paulo e Fernando Crespo Queiroz Neves

Parte 2: Temas Gerais

A construção do Direito Humano ao Alimento no plano internacional. 551 Tatiana de A. F. R. Cardoso Squeff

Grupos vUlNERABles de ESPECIAL PROTECCIÓN POR PARTE DEL INSTITUTO NACIONAL DE Derechos Humanos (INDH) ¿EN QUIÉN PODRÍA Y DEBERÍA ENFOCARSE EN BASE A LA DOCTRINA Y A LA EXPERIENCIA COMPARADA IBEROAMERICANA?

Juan Pablo Díaz Fuenzalida

El SUFRAGIO ELECTRÓNICO COMO ALTERNATIVA AL SUFRAGIO TRADICIONAL: LUCES Y SOMBRAS DE UN DEBATE RECURRENTE 595

David Almagro Castro, Felipe Ignacio Paredes Paredes e Edgardo Lito Andres Cancino

Cognoscibilidade E CONTROLE SOCIAL dA TRANSPARÊNCIA PÚbliCA SOB A ÉGIDE DA DEMODIVERSIDADE: ESTUDO EMPÍRICO DE PORTAIS ELETRÔNICOS MINISTERIAIS LATINOAMERICANOS

Ana Carolina Campara Verdum, Leonardo Fontana Trevisan e Rosane Leal da Silva

DESAFIOS E BENEFÍCIOS DA INTELIGÊNCIA ARTIFICIAL PARA O DIREITO DO CONSUMIDOR 655 Sthéfano Bruno Santos Divino

QUEM TEM MEDO DA RESPONSABILIZAÇÃo SUBJETIVA? As TEORIAS DA CONDUTA E DA IMPUTAÇÃO, PARA UM DIREITO ADMINISTRATIVO SANCIONADOR CONSTITUCIONALIZADO...........................690 Sandro Lúcio Dezan e Paulo Afonso Cavichioli Carmona

A INSUfiCiÊNCIA dE TRIBUTAÇÃo COMO FUNDAMENTO PARA O AFASTAMENTO DA RESERVA DO POSSÍVEL NA GARANTIA DO MÍNIMO EXISTENCIAL E DA DIGNIDADE HUMANA. 711 Dione J. Wasilewski e Emerson Gabardo 


\title{
El sufragio electrónico como alternativa al sufragio tradicional: luces y sombras de un debate recurrente
}

\author{
The electronic suffrage as an alternative \\ to the common one: lights and shadows of a \\ circular debate.
}

\author{
David Almagro Castro** \\ Felipe Ignacio Paredes Paredes*** \\ Edgardo Lito Andres Cancino****
}

\section{Resumen}

El presente artículo de investigación analiza los beneficios e incertidumbres que conlleva la implantación del sufragio electrónico como herramienta de modernización e incremento de la participación electoral. Este análisis se desarrolla utilizando una metodología doble: el análisis dogmático y la praxis que nos ofrece el recurso, parcial por cuestiones de oportunidad, al Derecho comparado brasileño y estonio. Como conclusiones principales puede afirmarse que el análisis de las características y los tipos de sufragio electrónico revelan la existencia de ciertas ventajas plausibles que, por el contrario, no parecen compensar los riesgos relativos a posibles vulneraciones de algunas características estructurales del sufragio.

Palabras Claves: Derecho de sufragio activo. Sufragio electrónico. Participación electoral. Democracia.

* Recebido em 08/03/2021

Aprovado em 09/03/2021

** Doctor en Derecho por la Universidad de Sevilla y PUCRS. Profesor Adjunto, Universidad Austral (Chile).

E-mail: davalmagrocastro@gmail.com

*** Doctor en Derecho por la Universitat Pompeu Fabra. Profesor Auxiliar, Universidad Austral (Chile).

E-mail: davalmagrocastro@gmail.com

**** Docente de Clínica Jurídica, Departamento de Derecho, Facultad de Ciencias Jurídicas Económicas y Administrativas, Universidad Católica de Temuco. Magíster en Derecho Público de la Universidad Católica de Temuco.

E-mail: ecancino2013@alu.uct.cl

\section{Abstract}

The current paper develops an investigation concerning the benefits and drawbacks about the implementation of the electronic suffrage as a tool for modernizing and reinforce the electoral participation. In order to achieve the main goal, we will use a combined methodology: a dogmatic analysis as well as the empirical results provided by using the comparative law in Brazil and Estonia. As main result, it seems obvious that the undeniable benefits of the electronic suffrage are fewer to the uncertainties and risks related with a more than possible violation of some key notes of the right to vote.

Keywords: Right to vote. Electronic suffrage. Electoral participation. Democracy 


\section{Introducción}

La discusión académica sobre los beneficios e incertidumbres que conlleva sustituir el sufragio tradicional por el sufragio electrónico puede considerarse un debate de ida y vuelta en el mundo académico y con puntual eco en los operadores políticos. El centro del debate gira en torno a la cuestión de si la implantación del sufragio electrónico mejoraría el normal desarrollo de los procesos electorales, incrementaría la participación electoral y resguardaría las características básicas del derecho de sufragio en su conjunto. En este sentido, la irrupción de la COVID-19 ha producido un verdadero seísmo en materia de reconfiguración de derechos fundamentales y, obviamente, el derecho de sufragio no es una excepción.

Afirmar que el sufragio electrónico tiene el potencial de dinamizar la participación electoral y garantizar las características básicas inherentes al ejercicio del derecho de sufragio activo exige el análisis de su naturaleza jurídica, de sus características esenciales y los posibles efectos que su sustitución por el modelo electrónico tendría sobre las características esenciales del derecho de sufragio tal y como es reconocido en práctica unanimidad de los sistemas democráticos actuales.

El análisis dogmático anteriormente referido se completa con el estudio de dos experiencias empíricas de Derecho comparado en materia de sufragio electrónico: Brasil y Estonia. Como se verá, una y otra arrojan luces y sombras. La propuesta metodológica se completa con el estudio de las garantías básicas del derecho fundamental de sufragio, dirigida a verificar el grado de cumplimiento de las mismas asociado a una hipotética implantación del sufragio electrónico.

\section{El derecho de sufragio: notas esenciales}

Cualquier sistema político que se defina como democrático lleva aparejado consigo el reconocimiento del derecho de sufragio como elemento estructurante del sistema en general y de las instituciones representativas estatales en particular. Es a través de su ejercicio como los ciudadanos participan e intervienen directa e indirectamente en la producción normativa y algunas decisiones propias de los asuntos públicos ${ }^{1}$. Dicho en otros términos: el sufragio se configura prima facie como un instrumento por el cual los ciudadanos pueden expresar sus preferencias, participar en la decisión de los asuntos políticos y generar representación ${ }^{2}$. Este punto de partida, insoslayable, no impide afirmar que la concepción del sufragio en del sistema democrático no ha de obedecer a una visión meramente instrumental o funcional del mismo. Su innegable carácter de derecho fundamental exige realizar una aproximación sucinta a su compleja naturaleza jurídica.

Como es bien sabido, el derecho de sufragio encuentra en las revoluciones político-burguesas de fines del siglo XVIII sus fundamentos epistemológicos modernos. La Revolución francesa, en efecto, produjo un desplazamiento del poder político desde la figura del monarca hacia la Nación como titular último de dicho poder. Su definición como ente abstracto incapaz de ejercer el poder soberano por sí mismo trajo consigo el germen de la teoría de la representación moderna, entendida como acto de delegación del poder soberano en un conjunto de representantes elegidos a través del derecho de sufragio que, en su formulación originaria, sería censitario.

En este contexto de cambio de paradigma en la residenciación y organización del poder político se originaría y consolidaría con el paso de las décadas la discusión moderna sobre la naturaleza jurídica del sufragio. Dos serían las concepciones elementales: a) el sufragio como derecho por antonomasia del pueblo titular del poder político; b) el sufragio como medio a través del cual se daba cumplimiento a la obligación que genera la titularidad de la soberanía nacional. Esta discusión sentaría las bases de la comprensión futura del sufragio como derecho o como función; el correr de las décadas abriría paso a una tercera postura, calificable de ecléctica, que

PAREDES, Felipe. Teoría Constitucional y Bases de la Institucionalidad. Valencia: Tirant lo Blanch, 2020. p.185.

CARRO, Antonio. Derecho Politico. Madrid: Editorial Universidad de Madrid, 1959. p. 355. 
haría del sufragio un derecho-deber. Esta posición se consolidaría durante el siglo XX y tendría su expresión en no pocas Constituciones del último tercio del siglo XX. Valga como ejemplo su presencia mayoritaria en textos constitucionales del ámbito sudamericano como Brasil, Ecuador, Bolivia, Argentina, etc...

La concepción del sufragio como derecho encuentra sus orígenes en la teoría de la soberanía popular elaborada por Rousseau que, como es sabido, se hallaba compuesta por tantas fracciones como ciudadanos tuviere el Estado y que se expresaría a través del sufragio ${ }^{3}$. El marcado carácter liberal de esta teoría llevaría aparejada la comprensión del sufragio como derecho individual absoluto, de oposición frente al poder estatal y expresión de la libertad personal de sus titulares. Por esta razón, su ejercicio no podría ser obligatorio ${ }^{4}$.

Por su parte, el sufragio como función pública se construiría sobre la base de la Nación como titular de la soberanía y el Estado como titular de todas las funciones y potestades públicas. En este sentido, el sufragio es solo parte de las potestades del Estado y su ejercicio por los ciudadanos es un acto obligatorio que garantiza la renovación periódica de las instituciones. De esta forma, y por oposición a la teorización anterior, el sufragio no sería considerado un derecho individual ni una libertad de la cual son titulares todos los individuos ${ }^{5}$. El sufragio como función tendría, por el contrario, carácter restringido y se reservaría a las personas que cumpliesen ciertas condiciones ${ }^{6}$. En este marco intelectual el pueblo, ente carente de poder, se convierte en un simple órgano del Estado que debe cumplir una función pública a través del ejercicio del sufragio en la forma dispuesta por la Constitución y las leyes?.

Como síntesis de las teorías anteriores surgiría una noción dualista del sufragio según la cual el elector es titular de un derecho y sujeto investido de una función pública. El derecho corresponde al reconocimiento del estatus de ciudadano, siendo el elector titular de un derecho garantizado por el ordenamiento jurídico que le permite votar y presentarse como candidato en la medida que cumpla los requisitos exigidos por la ley. Por su parte, la función es el poder otorgado a un individuo que, teniendo la calidad de ciudadano, es llamado a ejercer una función pública ${ }^{8}$. En esta concepción el sufragio, con independencia de su modalidad o periodicidad, es un derecho y un deber que se inserta dentro de los derechos políticos de los ciudadanos, instrumentos a través de los cuales participan de los asuntos públicos en el Estado?.

Situándonos en el marco del Estado democrático como forma natural y mayoritaria de organización del poder político, dos son las consecuencias lógicas que se siguen: a) la condición del principio democrático como elemento estructurante del mismo; b) la participación política elemento nuclear de la legitimidad de las instituciones representativas estatales ${ }^{10}$. Esta comprensión de la fundamentación y organización del poder político trae consigo la caracterización mayoritaria del sufragio como derecho fundamental ${ }^{11}$.

HERRERA, Edgard; VILLALOBOS, Enrique. Sufragio y Principio democrático: Consideraciones sobre su existencia y vinculancia. Revista de Derecho Electoral, n. 1, p. 89-108, primer semestre 2006.

4 Sierra, Lucas. El Voto como Derecho: Una Cuestión de Principios. Em: Fontaine, Arturo; Larroulet, Cristián; Viera-Gallo, José; Walker, Ignacio (ed.). Modernización del Régimen Electoral Chileno. Santiago de Chile-CIEPLAN, 2007. p. 157-181. Disponible em: https:// www.cieplan.org/wp-content/uploads/2019/12/Modernizacion-del-regimen-electoral-chileno.pdf. Acceso: 05 mar. 2021. En el mismo sentido SOTO, Francisco. Reflexiones sobre el voto obligatorio. Revista de Derecho Público de la Universidad de Chile, p. 339-351, 2018.

5 URBINA, Francisco. Derecho de Sufragio: La debatida cuestión de su obligatoriedad. En Estudios Constitucionales, v. 7, n. 1, p. 361-384, 2009.

6 GÁLVEZ, Luis. El Derecho de Sufragio en el Siglo XX. En Derechos y Libertades de la Universidad Carlos III de Madrid, n. 31, p. 163-189, jun. 2014.

ARAGÓN, Manuel. Derecho de sufragio: principio y función. En: NOHLEN, Dieter; ZOVATTO, Daniel; OROZCO, Jesús; THOMPSON, José (comp.). Tratado de Derecho Electoral comparado de América Latina. 2. ed. México: FCE, Instituto Interamericano de Derechos Humanos, Universidad de Heidelberg, International IDEA, Tribunal Electoral del Poder Judicial de la Federación, Instituto Federal Electoral, 2007. p. 162-173.

8 DUGUIT, León. Manual de Derecho Constitucional. Madrid: Librería F. Beltrán, 1926. p. 135. (Traducción, prólogo y apéndice de ACUÑA, José).

9 En este sentido, es interesante señalar que existe una variante de la concepción clásica de sufragio como derecho- función elaborada por la doctrina italiana y que considera el sufragio como un derecho corporativo cuyo ejercicio es de carácter colectivo y en esencia público. 10 PRESNO, Miguel. El derecho de voto como derecho fundamental. Revista Mexicana de Derecho Electoral, n. 2, p. 109-151, jul./ dic. 2012.

11 FERRAJOLI, Luigi. Los Fundamentos de los Derechos Fundamentales. Madrid: Trotta, 2001. p. 40. Traducción de DE CABO, Anto- 
El contenido del derecho fundamental de sufragio faculta a los ciudadanos para que intervengan en la adopción de las decisiones políticas y en la formación de las normas a través de las que se expresa la voluntad popular ${ }^{12}$. En este sentido, el derecho de sufragio se concibe desde una doble perspectiva: en su dimensión subjetiva, como la libertad que tienen los ciudadanos para participar en la articulación de la voluntad estatal; desde una perspectiva objetiva, como un elemento de legitimidad del sistema político democrático ${ }^{13}$. Es en este punto donde se pone de manifiesto la complejidad de la naturaleza del sufragio. Por una parte, se trata de un derecho individual que corresponde a cada uno de los ciudadanos. Por otra, es también un derecho con una clara dimensión institucional que se ejerce colectivamente con la finalidad de reconocer la voluntad de un pueblo que, a la postre, legitima las decisiones en un Estado democrático ${ }^{14}$.

La renovación del circuito de legitimidad propio del sistema democrático requiere del equilibrio entre las perspectivas subjetiva y objetivo-institucional del sufragio ${ }^{15}$; de lo contrario, se desnaturalizaría el derecho y se condicionaría su naturaleza jurídica auténtica. Bajo el pretexto de asegurar mayores niveles de participación se podría afectar la cláusula de esencialidad de este derecho fundamental o bien, buscando garantizar la libertad personal de los free riders, se podría debilitar el sistema democrático ${ }^{16}$. Esta es la lógica bajo la cual debe ser comprendida la compleja naturaleza del sufragio como derecho. Paralelamente, deben descartarse las concepciones que condicionan la naturaleza jurídica del voto a la obligatoriedad o voluntariedad de su ejercicio al no ser características relevantes en la delimitación de su contenido ${ }^{17}$.

En esencia, el derecho fundamental de sufragio garantiza la participación política libre e igualitaria de los ciudadanos con la finalidad de que sus preferencias en los procesos electorales sean garantizadas por el ordenamiento jurídico ${ }^{18}$. Su radio de acción no cubre todas las expresiones propias de la participación política, circunscribiéndose a la facultad que tienen los ciudadanos de elegir representantes públicos, la adopción de determinadas decisiones políticas, la participación en la formación de la ley y la posibilidad - mediatizada ampliamente por los partidos - de concurrir a las elecciones como candidatos ${ }^{19}$. En este contexto, garantizar el libre ejercicio de la participación política conlleva que el derecho de sufragio genere obligaciones de carácter jurídico al Estado, quien debe proporcionar las condiciones y mecanismos para que los ciudadanos puedan participar en elecciones periódicas y libres. De igual forma, y como complemento de la obligación anterior, debe abstenerse de realizar actuaciones que pongan en entredicho el libre ejercicio del sufragio en su doble vertiente activa y pasiva ${ }^{20}$.

Sobre las obligaciones prestacionales que el derecho de sufragio exige del Estado, su condición de derecho constitucionalmente reconocido le hace acreedor de una jerarquía normativa superior en el ordenamien-

nio y PISARELLO, Gerardo.

12 PRESNO, Miguel. El derecho de voto como derecho fundamental. Revista Mexicana de Derecho Electoral, n. 2, p. 109-151, jul./ dic. 2012.

13 ARAGÓN, Manuel. Derecho de sufragio: principio y función. En: NOHLEN, Dieter; ZOVATTO, Daniel; OROZCO, Jesús; THOMPSON, José (comp.). Tratado de Derecho Electoral comparado de América Latina. 2. ed. México: FCE, Instituto Interamericano de Derechos Humanos, Universidad de Heidelberg, International IDEA, Tribunal Electoral del Poder Judicial de la Federación, Instituto Federal Electoral, 2007.

14 Gálvez, Luis. El Derecho de Sufragio en el Siglo XX. En Derechos y Libertades de la Universidad Carlos III de Madrid, n. 31, p. 163189, jun. 2014.

15 ARAGÓN, Manuel. Derecho de sufragio: principio y función. En: NOHLEN, Dieter; ZOVATTO, Daniel; OROZCO, Jesús; THOMPSON, José (comp.). Tratado de Derecho Electoral comparado de América Latina. 2. ed. México: FCE, Instituto Interamericano de Derechos Humanos, Universidad de Heidelberg, International IDEA, Tribunal Electoral del Poder Judicial de la Federación, Instituto Federal Electoral, 2007.

16 CHUAQUI, Tomás. Participación Electoral Obligatoria: Una Defensa. Em: Fontaine, Arturo; Larroulet, Cristián; Viera-Gallo, José; Walker, Ignacio (ed.). Modernización del Régimen Electoral Chileno. Santiago de Chile-CIEPLAN, 2007, p. 183-203. Disponible en https://www.cieplan.org/wp-content/uploads/2019/12/Modernizacion-del-regimen-electoral-chileno.pdf. Acceso: 05 mar. 2021.

17 MARSHALL, Pablo. El derecho y la obligación de votar. Revista de Derecho, Valdivia, v. XXII, p. 77-91, jul. 2009.

18 PRESNO, Miguel. El derecho de voto como derecho fundamental. Revista Mexicana de Derecho Electoral, n. 2, p. 109-151, jul./ dic. 2012.

19 Presno, Miguel. El Derecho de Voto. Madrid: Tecnos, 2003. p. 113.

20 MARSHALL, Pablo. El derecho y la obligación de votar. Revista de Derecho, Valdivia, v. XXII, p. 77-91, jul. 2009. 
to jurídico, de forma que su regulación normativa está sujeta al principio de reserva legal ${ }^{21}$. En otras palabras: los mecanismos de preparación, realización y calificación de elecciones, plebiscitos, referendos y toda otra actividad prestacional destinada a garantizar la participación política de los ciudadanos debe ser desarrollada por el Estado en virtud de una ley en sentido formal22.

Finalmente, el carácter fundamental del sufragio exige que la configuración normativa que el legislador realice sobre su contenido se halle limitada por la garantía constitucional del contenido esencial como límite a la acción reguladora y limitadora del legislador. Baste nombrar en este punto la imposibilidad de establecer legalmente la obligación de votar u otras prerrogativas que atenten contra el sufragio universal y el principio democrático ${ }^{23}$. Dicho en términos directos: en su acción reguladora y limitadora, el legislador solo podría disponer del contenido abstracto del sufragio en los términos previstos y autorizados por la Constitución, respetando en todo momento la cláusula de esencialidad del derecho ${ }^{24}$.

\section{La importancia del sufragio en el marco del Estado democrático}

El derecho de al sufragio ha sido conceptuado tradicionalmente como un mero derecho político y, consecuentemente, como una suerte de derecho de segunda categoría frente a otros derechos fundamentales imbuidos de mayor prestigio. Por el contrario, la noción de democracia agregativa hace del sufragio un derecho fundamental stricto sensu y epicentro de la articulación de la actual democracia representativa. Dicho de otra forma: sin la existencia y normal ejercicio del derecho fundamental de sufragio no es posible hablar de democracia ni, en consecuencia, de Estado democrático ${ }^{25}$.

El sufragio se configura como expresión básica de la libertad de los ciudadanos en el Estado democrático al permitir la participación política ciudadana en la conformación del orden social, proceso en virtud del cual se produce la identificación entre pueblo gobernante y pueblo gobernado ${ }^{26}$. Por medio del sufragio, los ciudadanos logran canalizar sus intereses y expectativas políticas hacia el Estado, posibilitando que la comunidad se autodetermine y decida sobre su propia orientación política; la ciudadanía supera, de esta forma, su rol de subordinación frente al Estado y la sustituye por un protagonismo -en la conformación de la voluntad popular, en las decisiones que adopten los órganos representativos y en las normas a las que estarán sometidos, eso sí, con diferentes manifestaciones e intensidades. El ejercicio del derecho fundamental de sufragio hace posible la conversión de la voluntad del pueblo en la voluntad del Estado, aproximando la realidad fáctica a una premisa básica de y en democracia: lograr el gobierno del pueblo y por el pueblo.

La complejidad de los Estados modernos y de los asuntos públicos requiere, para los adeptos de una visión conservadora, netamente representativa y elitista de la democracia que un alto porcentaje de las decisiones deban ser adoptadas por un grupo de profesionales de la política ${ }^{27}$. En consecuencia, la autodeterminación política del pueblo requiere de mecanismos de representación de los diversos intereses presentes en la sociedad. El más común es aquel por el cual los ciudadanos eligen un grupo de representantes públicos

\footnotetext{
21 Solozábal, Juan. Una revisión de la teoría de los derechos fundamentales. Revista Jurídica Universidad Autónoma de Madrid, n. 4 , ago. 2016 .

22 Solozábal, Juan. La actuación efectiva del proceso electoral y sus posibilidades. Revista Española de Derecho Constitucional, n. 70, p. 127-160, 2004.

23 Solozábal, Juan. La actuación efectiva del proceso electoral y sus posibilidades. Revista Española de Derecho Constitucional, n. 70, p. 127-160, 2004.

24 PRESNO, Miguel. El derecho de voto como derecho fundamental. Revista Mexicana de Derecho Electoral, n. 2, p. 109-151, jul./ dic. 2012.

25 PAREDES, Felipe. Teoría Constitucional y Bases de la Institucionalidad. Valencia: Tirant lo Blanch, 2020. p. 185.

26 Kelsen, Hans. Compendio de Teoría general del Estado. [S.1.]: Colofón, 1992. p. 224-225. (Traducción de Recaséns, Luis y de Ascárte, Justino).

${ }_{27}$ Bobbio, Norberto. El Futuro de la Democracia. México DF: Fondo de Cultura Económica de México, 1986. p. 33. (Traducción de Fernández, José).
} 
mediante el mecanismo de las elecciones periódicas, libres y competitivas. No resulta muy complejo deducir que esta noción de autogobierno, si puede llamarse así, es esencialmente reduccionista al quedar circunscrita a la elección de las autoridades conforme al principio mayoritario en las elecciones ${ }^{28}$.

Al ejercer la ciudadanía el derecho fundamental de sufragio se posibilita la elección de los representantes públicos, quienes asumen el rol de representación de las diferentes sensibilidades políticas existentes en la sociedad. De esta forma se genera y renueva periódicamente el circuito del gobierno representativo ${ }^{29}$; el sufragio produce, en consecuencia, el efecto jurídico de representación en el proceso de autodeterminación política de los ciudadanos de acuerdo a la lógica procesal inherente a las democracias que exige la renovación periódica de los representantes políticos ${ }^{30}$.

Ahora bien, la representación que se deriva del ejercicio del derecho fundamental de sufragio no se inscribe en la lógica del mandato imperativo en el que los representantes actúan como meros mandatarios de los intereses privados de sus electores. Por el contrario, la representación popular que emana del sufragio es aquélla en que los representantes actúan por cuenta de la Nación, bajo los limites establecido por la ley y la Constitución Política ${ }^{31}$. De esta forma, la accountability de los representantes públicos se posibilita mediante los controles normativos y políticos que establezca el ordenamiento jurídico. Tratándose de cargos de elección transitorios, como no puede ser de otra forma en democracia, los electores evaluarán su desempeño finalizado su respectivo período ${ }^{32}$. Este modus operandi hace de la naturaleza jurídica de la representación una relación de confianza entre los ciudadanos y representantes con elementos objetivos determinados por la responsabilidad y el control político sobre estos últimos ${ }^{33}$.

Por otra parte, el sufragio no solo produce representatividad en el espectro político. El prestigio de la democracia representativa también se sustenta en la legitimidad derivada de la participación política de los ciudadanos en los diferentes procesos electorales, entendidos como instancias en que los ciudadanos de manera libre e igualitaria ejercen el poder político del cual son titulares ${ }^{34}$. La legitimidad hace posible que las decisiones adoptadas por los representantes del pueblo se fundamenten en el hecho de haber sido elegidos por los ciudadanos como titulares del poder ${ }^{35}$.

Como corolario de lo anterior, puede afirmarse que la legitimidad democrática presupone el reconocimiento del derecho de sufragio a los ciudadanos con una finalidad específica: su ejercicio en elecciones libres y periódicas en las cuales se logren los consensos de la comunidad nacional para la posterior toma de decisiones públicas revestidas de aceptación al haber sido previamente validadas por la ciudadanía ${ }^{36}$.

28 Marshall, Pablo. El derecho a votar desde el extranjero. Revista de Derecho, Valdivia, v. XXIV, n. 2, p. 139-161, dic. 2011.

29 Sieyes, Emmanuel. ¿Qué es el tercer Estado? [S.1.]: Omegalfa, 2019. p. 61. Traducción en Clásicos de Historia.

30 Sebastián, Luis. Reflexiones sobre democracia y representación. El sistema electoral valenciano. En: Nicasio, Blanca y Pérez, Marta (ed.). Defender la Democracia. Estudios sobre la calidad democrática, buen gobierno y lucha contra la corrupción. Valencia: Tirant lo Blanch, 2020. p. 45-60.

31 Bastida, Francisco. Elecciones y Estado democrático de Derecho. Revista Española de Derecho Constitucional, n. 32, p. 115-134, 1991.

32 López, José; de Santiago, Monserrat. Significado y función del derecho de sufragio en la actividad electoral de un Estado democrático. Revista Novum Jus, v. 12, n. 1, p. 59-82, ene./jun. 2018.

33 Sebastián, Luis. Reflexiones sobre democracia y representación. El sistema electoral valenciano. En: Nicasio, Blanca y Pérez, Marta (ed.). Defender la Democracia. Estudios sobre la calidad democrática, buen gobierno y lucha contra la corrupción. Valencia: Tirant lo Blanch, 2020. p. 45-60.

34 Marshall, Pablo. Elecciones representativas y legitimidad democrática: una mirada desde las concepciones normativas de la democracia. Revista de Derecho, Valdivia, v. XXX, n. 2, p. 275-299, dic. 2017.

35 García, María. Elementos de Derecho Electoral. Valencia: Tirant lo Blanch, 2010. p. 23.

36 Bobbio, Norberto. El Futuro de la Democracia. México DF: Fondo de Cultura Económica de México, 1986. p. 33. Traducción de Fernández, José. 


\section{El sufragio electrónico: aspectos generales}

El reconocimiento, identificación y aceptación de determinadas categorías jurídicas por una determinada comunidad es un proceso dinámico que admite variaciones y mutaciones progresivas en atención a los cambios que experimentan las sociedades democráticas de forma natural ${ }^{37}$. Este dinamismo epistemológico afecta al derecho de sufragio que, como puede fácilmente deducirse, se encuentra supeditado por factores políticos, legales, electorales, sociológicos y tecnológicos que pueden condicionar y redefinir su contenido y alcance ${ }^{38}$.

En este punto, el estado de avance tecnológico característico de la sociedad de la información y del conocimiento permite valorar la conveniencia de sustituir el sufragio tradicional basado en las papeletas o cédulas electorales por el sufragio electrónico como herramienta de modernización y perfeccionamiento de las instituciones democráticas. Dicho en términos directos: se trata de analizar si la aplicación de Tecnologías de la Información y Comunicación (en adelante, TIC) en los procesos electorales podría suponer un cambio de paradigma en la forma en que tradicionalmente se ha ejercido el derecho fundamental de sufragio ${ }^{39}$.

La inclusión de la tecnología en los procesos electorales se debe sistematizar en tres niveles diferentes en función del mayor o menor nivel de penetración de las TIC en el proceso electoral ${ }^{40}$. Esta circunstancia imposibilita establecer un concepto general de sufragio electrónico al estar condicionado a una mayor o menor inserción de la tecnología en el sistema de votación. El sufragio electrónico es, como ya se deslizó al inicio de este apartado, un concepto dinámico como la propia tecnología, no limitado a la acción de votar por medio de dispositivos electrónicos; debe, por el contrario, considerar la aplicación de TIC en las diversas etapas que conforman el proceso electoral.

Los niveles de inserción tecnológica en las elecciones son, como ya hemos indicado, diferentes en función de la naturaleza del proceso electoral. En un primer estadio se encuentran los sistemas de votación con baja o nula penetración de TIC en los que el elector no tiene una vinculación directa con los medios o dispositivos tecnológicos; en este escenario, es la papeleta o cédula introducida manualmente en la urna o perforada el elemento sometido a los mecanismos tecnológicos de recuento y procesamiento de información ${ }^{41}$. En este nivel se considera que la inscripción, identificación y votación de los electores se realiza de forma manual, teniendo el recuento de votos y procesamiento de datos carácter electrónico ${ }^{42}$. Como es fácilmente deducible, es esta la etapa de tecnificación en la que se encuentran inmersos la mayoría de los sistemas de votación. Hablamos, en consecuencia, de los sistemas tradicionales de papel, de los sistemas de votación mediante tarjeta perforada ${ }^{43}$ y los mecanismos de voto mediante aparato lector ${ }^{44}$.

En el segundo nivel de tecnificación se incluye el registro electrónico de los electores, su autentificación y el conteo electrónico de los votos ${ }^{45}$. En este escenario, la acción de votar se realiza por medio de diferentes

\footnotetext{
37 Barrientos, Fernando. Dimensiones discursivas en torno al voto electrónico. Revista de Ciencia Política, Pontifica Universidad Católica de Chile, v. 27, n. 1, p. 111-131, 2007.

38 Tula, María Inés. Democracia, elecciones y nuevas tecnologías. El voto electrónico. Revista Mexicana de Análisis Político y Administración Pública, Universidad de Guanajuato, v. 1, n. 2, p. 9-21. jul./dic. 2012.

39 González, Luis. Voto electrónico por internet y riesgos para la democracia (I). Revista de Derecho Político, Universidad Nacional de Educación a Distancia, n. 74, p.163-209, ene./abr. 2009.

40 Aleuy, Mahmud. La votación electrónica. Em: Fontaine, Arturo; Larroulet, Cristián; Viera-Gallo, José; Walker, Ignacio (ed.). Modernización del Régimen Electoral Chileno. Santiago de Chile-CIEPLAN, 2007. p. 221-240. Disponible en http://www.cieplan.org/ media/publicaciones/archivos/112/Capitulo_2.pdf. Acceso: 05 mar. 2021.

41 Téllez, Julio. El Voto Electrónico. Coyoacán: Tribunal Electoral del Poder Judicial de la Federación, 2010. p. 26.

42 Aleuy, Mahmud. La votación electrónica. Em: Fontaine, Arturo; Larroulet, Cristián; Viera-Gallo, José; Walker, Ignacio (ed.). Modernización del Régimen Electoral Chileno. Santiago de Chile-CIEPLAN, 2007. p. 221-240. Disponible en http://www.cieplan.org/ media/publicaciones/archivos/112/Capitulo_2.pdf. Acceso: 05 mar. 2021.

43 Se trata de dispositivos que son capaces de reconocer las perforaciones realizadas por los votantes en las papeletas, haciendo con posterioridad el recuento de las perforaciones asignadas a cada opción, calculando así el número de votos asignado a cada una de ellas.

44 En este caso son dispositivos electrónicos que pueden reconocer las marcas realizadas por los electores en las cédulas o papeletas, haciendo la lectura de las opciones seleccionadas y el recuento de los votos.

${ }_{45}$ Aleuy, Mahmud. La votación electrónica. Em: Fontaine, Arturo; Larroulet, Cristián; Viera-Gallo, José; Walker, Ignacio (ed.).
} 
dispositivos electrónicos como computadores, escáneres, máquinas electrónicas de votación y, en particular, dispositivos de votación tipo DRE (direct recording electronic) ${ }^{46}$. Resulta posible, en este contexto, hablar de sufragio electrónico propiamente dicho, pues con independencia de los diferentes tipos de tecnologías o mecanismos que se utilicen en el proceso, los electores se vinculan de manera directa y presencial con la tecnología ${ }^{47}$. En termino generales, el proceso electoral se desarrolla en los diversos locales de votación establecidos por la autoridad correspondiente, existiendo quioscos o máquinas similares a cajeros automáticos que permiten identificar las diversas opciones de votación y en las cuales los electores deben marcar o seleccionar su preferencia. Una vez que emitido el sufragio, queda registrado en el dispositivo que realizará el proceso de almacenamiento y recuento de votos.

Como resulta evidente, es en el tercer nivel donde existe una mayor integración de las TIC en el proceso electoral. En este contexto, las elecciones se realizan en su totalidad por medio de dispositivos electrónicos, pudiendo incluso ejercerse el «sufragio en ausencia» por medio del voto por internet. En esta modalidad los electores votan sin necesidad de acudir a los centros de votación, valiéndose de computadores, tablets, teléfonos inteligentes u otros dispositivos ${ }^{48}$.

El e-voto o voto por internet es un tipo de voto electrónico que cuenta con un nivel de complejidad e integración de TIC superior a la urna electrónica. En este sistema de votación, los datos de los electores se encuentran previamente registrados en las bases de datos de los órganos electorales y los votantes, por medio de sus respetivas claves de acceso, ingresan a la plataforma destinada para la votación y seleccionan al candidato u opción de su preferencia. Finalmente, el sufragio emitido por estas plataformas es encriptado y enviado a una urna electrónica central que realiza el proceso general de conteo de votos ${ }^{49}$.

De la exposición previa se puede deducir fácilmente que el voto electrónico presencial y el voto por internet no se encuadran en la misma figura; sin embargo, ambos conceptos se pueden englobar bajo el término genérico de sufragio electrónico. Considerando que una y otra figura son objeto de valoraciones no exentas de controversia y sombras en relación a su implementación, se entiende de utilidad desarrollar los argumentos a favor y en contra de su implementación.

Comenzando por los beneficios de la implantación, los partidarios del voto electrónico afirman que facilitaría el desarrollo del proceso electoral al promover la captación rápida y confiable de los votos, los resultados y, paralelamente, reducir in extremis el riesgo de fraude electoral derivado de la intervención humana que presentan los sistemas tradicionales de votación ${ }^{50}$. La automatización del proceso reduce los tiempos requeridos para conocer los resultados finalizada la elección al ser una operación realizada directamente por el software del sistema ${ }^{51}$.

La rapidez y limpieza en el conteo de votos no es el único beneficio de la implantación del sistema electrónico. La utilización de dispositivos tecnológicos conlleva también una reducción considerable de los costos económicos para el Estado al ser susceptibles de reutilización en procesos posteriores y ser sus costos de mantenimiento relativamente bajos. La logística inherente a la celebración de los comicios electorales tam-

Modernización del Régimen Electoral Chileno. Santiago de Chile-CIEPLAN, 2007. p. 221-240. Disponible en http://www.cieplan.org/ media/publicaciones/archivos/112/Capitulo_2.pdf. Acceso: 05 mar. 2021.

46 Tula, María Inés. Democracia, elecciones y nuevas tecnologías. El voto electrónico. Revista Mexicana de Análisis Político y Administración Pública, Universidad de Guanajuato, v. 1, n. 2, p. 9-21. jul./dic. 2012.

47 Países como Estados Unidos, Brasil, India o Nueva Zelanda han implementado sistemas de votación electrónica que pueden ser clasificados en esta categoría.

48 Marshall, Pablo. Sufragio por Internet: análisis teórico y comparado. Revista Mexicana de Derecho Constitucional Cuestiones Constitucionales, Universidad Nacional Autónoma de México, n. 39, p. 261-293, jul./dic. 2018.

49 Barrientos, Fernando. Dimensiones discursivas en torno al voto electrónico. Revista de Ciencia Política, Pontifica Universidad Católica de Chile, v. 27, n. 1, p. 111-131, 2007.

50 González, José; del Nogal, José; Müller, Roger. Venezuela: El voto electrónico. Auditorias y legitimidad del sistema automatizado de votación. Revista Espacio Abierto, Universidad del Zulia, v. 21, n. 2, p. 305-321, abr./jun. 2012.

51 Fernández, Rosa. El voto electrónico: El caso vasco. Revista de Estudios Políticos, Centro de Estudios Políticos y Constitucionales, n.112, p. 199-236, abr./jun. 2001. 
bién se ve optimizada al reducirse las necesidades de contar con mesas electorales y los recursos humanos y económicos asociados a su constitución ${ }^{52}$. Otro beneficio adicional sería el medioambiental, consecuencia de una reducción drástica o completa eliminación de las papeletas o cédulas ${ }^{53}$.

Los beneficios de la implantación del sufragio electrónico van más allá de las cuestiones logísticas, de conteo de sufragio y medioambientales. Inciden igualmente en uno de los problemas estructurales que aqueja a las democracias representativas actuales: el alto nivel de abstencionismo de los jóvenes en los procesos electorales. En este sentido, parte de la doctrina afirma que las innovaciones tecnológicas y el uso del e-voto podría aumentar los niveles de participación de los jóvenes en atención a dos argumentos. En primer lugar, la propia inercia de las sociedades hiperconectadas ha inundado de tecnología todos los ámbitos de la vida; esta realidad afecta igualmente a los procesos propios de la democracia, entre los cuales se encuentran los procesos electorales y de participación que, de realizarse electrónicamente, serían más accesibles ${ }^{54}$. El segundo argumento es de índole económico y está asociado a la eliminación de los costes económicos y de tiempo por desplazamiento al centro de votación. Dicho en términos directos: el sufragio electrónico emitido desde el hogar estimularía la participación ciudadana en los comicios electorales al facilitar la logística y reducir los costos económicos asociados al proceso de votación ${ }^{55}$.

Como tercer argumento, los impulsores del sufragio electrónico esgrimen cuestiones de justicia reparativa e inclusión de ciertas minorías que tradicionalmente han sido excluidas de las elecciones tradicionales en sociedades de marcados rasgos multiculturales ${ }^{56}$. El sufragio electrónico, en efecto, otorga la posibilidad de crear interfaces en varios idiomas facilitando la votación de aquellas minorías en contextos de pluralidad lingüística. También se favorecería la mayor inclusión de personas analfabetas al hacer posible la identificación del candidato por medio de una fotografía o los símbolos de su partido o coalición; de esta forma, el acto de sufragar se vuelve sumamente intuitivo ${ }^{57}$. Por último, y en virtud del principio de universalidad del sufragio, cabe esperar que los sistemas de votación electrónica sean diseñados con la finalidad de aprovechar al máximo todas las ventajas que la tecnología puede ofrecer a las personas con discapacidades ${ }^{58}$.

Otra de las ventajas asociadas al sufragio electrónico, especialmente en la modalidad de voto por internet, dice relación con la mejora de la eficiencia del proceso democrático, ya que la web permite una mayor interacción entre los ciudadanos y sus gobiernos. En un contexto de uso normalizado de internet, el ciudadano tiene fácil acceso a la información relevante para la formación de su opinión política. La obtención de mayores caudales de información le permitiría aumentar las habilidades deliberativas y, de esta forma, estimular su participación directa. En esta formulación, no exenta de cierto idealismo, se fomenta el reemplazo de la democracia representativa agregativa por un modelo orientado al fortalecimiento de la democracia directa. Internet se configura como una suerte de ágora virtual en que los ciudadanos pueden participar activamente en cualquier tiempo y lugar en la toma de decisiones relevantes en la conducción del Estado ${ }^{59}$.

\footnotetext{
52 Barrientos, Fernando. Dimensiones discursivas en torno al voto electrónico. Revista de Ciencia Politica, Pontifica Universidad Católica de Chile, v. 27, n. 1, p. 111-131, 2007.

53 Gálvez, Luis; Ruiz, José. El voto electrónico y el test de calidad; o de cuatro bodas complicadas y un posible funeral. Revista de Derecho Politico, Universidad Nacional de Educación a Distancia, n. 81, p. 253-274, mayo/ago. 2011.

54 González, José; del Nogal, José; Müller, Roger. Venezuela: El voto electrónico. Auditorias y legitimidad del sistema automatizado de votación. Revista Espacio Abierto, Universidad del Zulia, v. 21, n. 2, p. 305-321, abr./jun. 2012.

55 Marshall, Pablo. Sufragio por Internet: análisis teórico y comparado. Revista Mexicana de Derecho Constitucional Cuestiones Constitucionales, Universidad Nacional Autónoma de México, n. 39, p. 261-293, jul./dic. 2018.

56 Marshall, Pablo. Sufragio por Internet: análisis teórico y comparado. Revista Mexicana de Derecho Constitucional Cuestiones Constitucionales, Universidad Nacional Autónoma de México, n. 39, p. 261-293, jul./dic. 2018.

57 Presno, Miguel. Premisas para la introducción del voto electrónico en la legislación electoral española. Revista de Estudios Políticos, Centro de Estudios Politicos y Constitucionales, n. 173, p. 277-304. Jul./sep. 2016.

58 Comité de Ministros del Consejo de Europa. Recomendación a los Estados miembros sobre los estándares legales, procedimentales y técnicos de los sistemas de votación electrónica. Estrasburgo. 2004. Disponible en: https://www.coe.int/t/dgap/goodgovernance/Activities/KeyTexts/Recommendations/E-votingRec_Spanish.asp. Acceso: 05 mar. 2021.

59 Aguirre, Jorge. Aportes de la web a la participación ciudadana y la representatividad democrática. Revista Chilena de Derecho y Tecnologia, Centro de Estudios en Derecho Informático de la Universidad de Chile, v. 4, n. 1, p. 145-186, primer semestre, 2015.
} 
Respecto a la mejora de los procesos democráticos, se viene sosteniendo que votar en ausencia, es decir, por correo o por internet genera beneficios sociales ya que, de forma previa a la votación, los electores tienen la posibilidad de discutir libremente y de manera abierta sobre las diversas opciones disponibles en su entorno social ${ }^{60}$. De esta forma, se incentiva la deliberación política y el acto de votar se vuelve más reflexivo, frente a la experiencia atomizada y solitaria de votar en una cabida cerrada ${ }^{61}$.

Como se indicó en párrafos precedentes, el sufragio electrónico también presenta carencias o incertidumbres que conviene señalar para no incurrir en simplificaciones idealistas. En primer lugar, se ha sostenido que el sufragio electrónico presencial y el sufragio por internet adolecen de problemas de seguridad al ser los dispositivos electrónicos susceptibles de manipulación por terceros o por hackers profesionales y, por tanto, producirse fraude en el recuento de los $\operatorname{votos}^{62}$. No deben descartarse, tampoco, fallas técnicas que no sean advertidas por los observadores o funcionarios encargados de la elección.

El profesor Tokayi ha identificado como posibles riesgos de seguridad los siguientes: a) Inserción de código malicioso que consiste, en esencia, en que previamente a las elecciones se ataque el software de las máquinas de votación y se altere el sentido del voto seleccionado por los electores. La pantalla de la máquina de votación podría mostrar a los votantes las opciones seleccionadas y registrarse en la memoria interna del dispositivo de una manera diferente a la preferencia seleccionada; b) Ataques individuales en los locales de votación a las máquinas de votación en el momento de la votación o con anterioridad a las elecciones; b) Manipulación de los resultados electorales finalizadas las elecciones y habiéndose desarrollado íntegramente el proceso electoral por hackers profesionales que intenten modificar el resultado de las elecciones agregando votos, modificando los emitidos o suprimiéndolos. Esta actividad fraudulenta se podría desarrollar durante la transmisión de los votos desde las máquinas de votación a los registros centrales interceptando las conexiones web de traspaso de datos ${ }^{63}$.

La posibilidad de manipular los resultados de votación es más latente en los casos de voto por internet, pues el uso de la web supone que el voto emitido por un ciudadano podría salir del territorio nacional en que se ha emitido para luego regresar a las fronteras nacionales o viceversa, es decir, podría emitirse un voto utilizando el acceso a la web de otro país para luego el voto ingresar al territorio nacional. Ambas situaciones suponen que la información electoral pueda ser retransmitida e interceptada por dispositivos extranjeros, pudiendo incluso convertirse la externalización del sufragio en un problema de seguridad nacional ${ }^{64}$.

El problema de los riesgos y las deficiencias de seguridad del voto electrónico nos conduce a una segunda crítica: el posible menoscabo de la confianza pública en el proceso electoral ${ }^{65}$. En este sentido, se ha señalado que la implementación del voto electrónico supone que la revisión, regulación y control de los mecanismos de votación se lleva a cabo por un pequeño grupo de técnicos y expertos informáticos. Esta situación conlleva la exclusión de los ciudadanos comunes de la organización y supervisión del proceso electoral ${ }^{66}$.

La imposibilidad de supervisar las elecciones es un déficit innegable en comparación con los sistemas

\footnotetext{
${ }^{60}$ Estonia que, como veremos, en un caso paradigmático de éxito en la implantación del $e$ - voto tiene un modelo de votación que permite que los electores puedan votar en plazos que van desde los 3 a 10 días, sugiriendo con ello el aumento de las posibilidades deliberación y discusión política.

61 Richey, Sean. Who Votes Alone? The Impact of Voting by Mail on Political Discussion. Australian Journal of Political Science, v. 40, n. 3, p. 435-442, sep. 2005.

${ }^{62}$ Fernández, Rosa. El voto electrónico: El caso vasco. Revista de Estudios Políticos, Centro de Estudios Políticos y Constitucionales, n. 112, p. 199-236, abr./jun. 2001.

63 Tokaji, Daniel. The Paperless Chase: Electronic Voting and Democratic Values. Public Law and Legal Theory Working Paper, Obio State University Moritz College of Law. Series n. 25, p. 1-95, dic. 2004.

64 González, Luis. Voto electrónico por internet y riesgos para la democracia (I). Revista de Derecho Político, Universidad Nacional de Educación a Distancia, n. 74, p. 163-209, ene./abr. 2009.

65 González, Luis. Voto electrónico por internet y riesgos para la democracia (I). Revista de Derecho Político, Universidad Nacional de Educación a Distancia, n. 74, p. 163-209, ene./abr. 2009.

66 Fernández, Rosa. El voto electrónico: El caso vasco. Revista de Estudios Políticos, Centro de Estudios Políticos y Constitucionales, n. 112, p. 199-236, abr./jun. 2001.
} 
tradicionales, sistemas más inclusivos y transparentes que el voto electrónico. En las elecciones tradicionales los ciudadanos concurren libremente al conteo de votos y pueden participar en las auditorías de las elecciones con el único requisito de tener habilidades matemáticas básicas ${ }^{67}$. Por el contrario, la inclusión de las TIC en el proceso electoral y la implementación del voto electrónico desplaza el conteo de los votos a dispositivos tecnológicos y las auditorías las realizarán los especialistas informáticos y el organismo público correspondiente.

La innegable falta de control por parte de la ciudadanía introduce la incertidumbre y la falta de confianza en el proceso electoral, presentándose como los principales riegos del sufragio electrónico. Las elecciones, obvio es decirlo, son un asunto de primera relevancia que compete a todos los ciudadanos. Todos tienen derecho a entender, comprender y fiscalizar todas las etapas del proceso electoral sin necesidad de tener conocimientos técnicos especiales ${ }^{68}$. Dicho en términos directos: la falta de publicidad y de control por parte de los ciudadanos en los procesos de votación electrónica produce desconfianza en el sistema, desconfianza que se traduce en un retroceso sociopolítico frente a la legitimidad que otorga el escrutinio público y directo propio del sistema tradicional en papel ${ }^{69}$.

Otro de los aspectos negativos del sufragio electrónico - que contradice el argumento de su menor coste - gira en torno al elevado coste de su implementación. En este sentido, se debe distinguir el costo económico del costo humano. Sobre el primero, se afirma que resultaría extremadamente oneroso implementar un sistema electoral electrónico al deber adquirir las máquinas de votación o implementar una red segura en caso de optar por el e-voto. Al coste de adquisición se debe añadir el derivado del mantenimiento de todo el aparataje de votación, adquisición de licencias, permisos, software, hardware, etc.

Esta situación genera, a su vez, legítimas interrogantes: ¿debe el Estado fabricar o comprar las máquinas de votación a privados? ¿Ha de comprar o diseñar las patentes y licencias de uso? ¿El mantenimiento de los dispositivos de votación ha de ser responsabilidad de la administración electoral o de empresas particulares?

La obsolescencia de que adolecen los dispositivos tecnológicos es otro problema asociado a la implantación del sufragio electrónico ${ }^{70}$. El dinamismo inherente a las TIC, que implica la obsolescencia programada de los dispositivos y programas de uso, puede motivar la caducidad en cuestión de escasos años de los componentes asociados a la implementación del sufragio electrónico. La administración electoral, órgano rector de las elecciones, tiene las siguientes obligaciones: a) Mantener actualizados y funcionales los dispositivos de votación; b) Realizar testeos y pruebas pilotos que aseguren el correcto funcionamiento del sufragio electrónico $^{71}$. No es arriesgado afirmar, en relación a este punto, que los altos costos presupuestarios que supone la implementación del sufragio electrónico se constituyen en una verdadera barrera de entrada en países con bajos niveles de ingresos.

Los costos humanos asociados al sufragio electrónico no son un asunto menor y, en este punto, se ha planteado que la capacitación de los electores es crucial para el éxito del sufragio electrónico. El coste de socialización y aprendizaje por parte de los electores no debe ser menospreciado, pues conlleva la realización de actividades de difusión, pruebas piloto y capacitaciones que incluyen el uso de las máquinas electrónicas de votación, la familiaridad con el lenguaje tecnológico y la difusión de medidas de protección de datos per-

\footnotetext{
Viollier, Pablo; Riveros, Bastián. Voto electrónico en Chile: una evaluación desde una perspectiva técnica, jurídica y política. Revista Cultura-Hombre-Sociedad, Universidad Católica de Temuco, v. 28, n. 2, p. 12-40, dic. 2018.

68 Barrat, Jordi. Observación electoral y voto electrónico. Revista Catalana de Dret Públic, Generalitat de Catalunya: Escola d'Administració Pública de Catalunya, n. 39, p.277-296. diciembre 2009.

69 Presno, Miguel. Premisas para la introducción del voto electrónico en la legislación electoral española. Revista de Estudios Políticos, Centro de Estudios Politicos y Constitucionales, n. 173, p. 277-304, jul./sep. 2016.

70 Fernández, Rosa. El voto electrónico: El caso vasco. Revista de Estudios Políticos, Centro de Estudios Politicos y Constitucionales, n. 112, p. 199-236, abr./jun. 2001.

71 Tula, María Inés. Democracia, elecciones y nuevas tecnologías. El voto electrónico. Revista Mexicana de Análisis Político y Administración Pública, Universidad de Guanajuato, v. 1, n. 2, p. 9-21, jul./dic. 2012.
} 
sonales $^{72}$. La existencia de asimetrías entre grupos etarios en materia de TIC exige la creación de instancias de capacitación y participación para quienes, por razones de edad o por cualquier otro motivo, no comprendan los alcances del voto electrónico ${ }^{73}$.

Siendo todas estas carencias e incertidumbres dignas de atención, la principal crítica a la implementación del sufragio electrónico alude a la imposibilidad de salvaguardar las garantías mínimas del derecho fundamental de sufragio: el carácter secreto, libre e igualitario del voto. En relación al carácter secreto del sufragio las dudas se ciernen sobre ambas modalidades de sufragio, si bien afecta con especial intensidad al e-voto ante la probable intervención de hackers profesionales. Si no se quiere incurrir en un exceso de ingenuidad, ha de reconocerse que existen poderosas razones para pensar que terceros puedan interceptar, descubrir, conocer y divulgar el contenido del voto emitido de manera remota y conocerse la identidad de su emisor. No hay como negar que hay numerosas incertidumbres respecto a la salvaguarda del carácter secreto del sufragio ${ }^{74}$.

Incluso en una situación menos extrema que la intervención de un hacker, el sufragio por internet no permite asegurar completamente el carácter secreto del sufragio ante la inexistencia de los controles y los resguardos que se sí se favorecen en los locales o establecimientos de votación ${ }^{75}$.

En el caso del voto electrónico presencial, se viene afirmando que el carácter reservado del sufragio es susceptible de vulneración mediante la decodificación de emisiones electromagnéticas, la incorporación de dispositivos ajenos en las máquinas de votación e, inclusive, escaneos de teléfonos móviles ${ }^{76}$. En este sentido, hay evidencias empíricas de que resulta posible vincular el sufragio con la identidad de quien lo ha emitido, sobre todo cuando el padrón electoral digitalizado está incorporado a la máquina de votación ${ }^{77}$. Esta última situación merece especial atención, pues con el sufragio electrónico se da una particularidad que no ocurre con otras operaciones tecnológicas $(v \cdot g$, transferencias bancarias, reservas de vuelos, compras electrónicas, etc....) y es que, para un buen funcionamiento del sufragio electrónico, es necesario desvincular al elector del sufragio, resguardando al tiempo la integridad del mismo ${ }^{78}$.

Estrechamente relacionado con el carácter secreto del sufragio electrónico está la capacidad del ciudadano para impedir y resistir las intervenciones de terceros en su decisión, es decir, la garantía de la libertad del elector en la emisión de su sufragio. En relación al sufragio electrónico presencial no se vislumbran inconvenientes mencionables al desarrollarse, al igual que el sufragio tradicional en papel, en un entorno controlado en el cual los electores pueden marcar libremente su opción en una cámara secreta destinada a tal efecto. Las interrogantes surgen en la modalidad de sufragio por internet ante la inexistencia de mecanismos para asegurar la libertad de los electores. Es difícilmente negable que el elector puede estar sometido a mayores coacciones o amenazas en su hogar que en el centro electoral, con presencia siempre de las fuerzas y cuerpos de seguridad del Estado ${ }^{79}$. No hay que descartar las presiones familiares para inducir el sufragio en uno u

\footnotetext{
72 Tula, María Inés. Democracia, elecciones y nuevas tecnologías. El voto electrónico. Revista Mexicana de Análisis Político y Administración Pública, Universidad de Guanajuato, v. 1, n. 2, p. 9-21, jul./dic. 2012.

73 Viollier, Pablo; Riveros, Bastián. Voto electrónico en Chile: una evaluación desde una perspectiva técnica, jurídica y política. Revista Cultura-Hombre-Sociedad, Universidad Católica de Temuco, v. 28, n. 2, p. 12-40, dic. 2018. En igual sentido Padrón, Floralba. Evoting en Colombia: avances y desafíos en la implementación. Revista Derecho del Estado, Universidad de Externado de Colombia, n. 42 , p. 211-248, ene./abr. 2019.

74 González, Luis. Voto electrónico por internet y riesgos para la democracia (II). Revista Derecho Politico, Universidad Nacional de Educación a Distancia, n. 77, p. 213-249, ene./abr. 2010.

75 Marshall, Pablo. Sufragio por Internet: análisis teórico y comparado. Revista Mexicana de Derecho Constitucional Cuestiones Constitucionales, Universidad Nacional Autónoma de México, n. 39, p. 261-293, jul./dic. 2018.

76 Viollier, Pablo; Riveros, Bastián. Voto electrónico en Chile: una evaluación desde una perspectiva técnica, jurídica y política. Revista Cultura-Hombre-Sociedad, Universidad Católica de Temuco, v. 28, n. 2, p. 12-40, dic. 2018.

77 Tula, María Inés. Democracia, elecciones y nuevas tecnologías. El voto electrónico. Revista Mexicana de Análisis Político y Administración Pública, Universidad de Guanajuato, v. 1, n. 2, p. 9-21, jul./dic. 2012.

78 Fernández, Rosa. El voto electrónico: El caso vasco. Revista de Estudios Políticos, Centro de Estudios Politicos y Constitucionales, n. 112 , p. 199-236, abr./jun. 2001.

79 González, Luis. Voto electrónico por internet y riesgos para la democracia (I). Revista de Derecho Político, Universidad Nacional de Educación a Distancia, n. 74, p. 163-209, ene./abr. 2009.
} 
otro sentido al existir asimetrías de poder e influencia que pueden poner en tela de juicio la imprescindible libertad de sufragio ${ }^{80}$.

Sin perjuicio de lo anterior, se ha contraargumentado que el sufragio por internet sí garantiza la libertad de los electores; todos los ciudadanos cuentan con la capacidad para resistir presiones indebidas, valiendo como ejemplo el voto por correo. Por consiguiente, no existen motivos para pensar que una persona que emite el sufragio desde su hogar por medio de un dispositivo electrónico se encuentre más amenazada que aquella que concurre presencialmente a las oficinas de correo a depositar el sufragio previamente marcado ${ }^{81}$.

Respecto a la igualdad del sufragio no se visualizan mayores problemas con el sufragio electrónico presencial. Los mayores problemas de desigualdad surgen con el sufragio por internet, específicamente por problemas de seguridad tecnológica y de falta de integridad. No cabe descartar, en este punto, que un elector pueda votar en más de una ocasión o que resulte excluido del proceso electoral. Si bien estas situaciones no alterarían de manera sustancial el resultado de la elección atentan contra el principio universal de un ciudadano un voto $y$, en consecuencia, se desnaturaliza la garantía de igualdad inherente al derecho fundamental de sufragio ${ }^{82}$.

Por su parte, el sufragio por internet generaría un gran impacto en la igualdad del sufragio al aumentar la brecha digital existente ${ }^{83}$. El concepto de brecha digital se refiere a las asimetrías de acceso entre los diferentes sectores de una sociedad a las herramientas tecnológicas de la información, específicamente internet ${ }^{84}$. La introducción del sufragio por internet reforzaría el índice de participación de los sectores más acomodados de la sociedad y, como efecto paralelo, fomentaría la exclusión de los sectores más vulnerables. Estas circunstancias reforzarían los indicadores de desigualdad y dificultaría el desarrollo de una democracia más participativa y las imprescindibles políticas de promoción de la igualdad.

El sufragio electrónico, además de dificultar la participación transversal e igualitaria de todos los electores en el proceso democrático, tiene nula incidencia en los niveles de participación política en las elecciones. En este sentido, el sufragio electrónico se puede considerar análogo al sufragio postal o por correspondencia. En ambos casos, la praxis ha evidenciado que tales modalidades no han tenido siquiera un impacto marginal en el aumento de la participación política ${ }^{85}$.

\section{El sufragio electrónico en el Derecho comparado: los casos brasileño y estonio}

Recurrir al Derecho comparado pone de manifiesto la existencia y vigencia del sufragio electrónico en diferentes países del mundo que no necesariamente responden a tradiciones políticas, económicas, sociales o culturales similares. Las experiencias comparadas incluyen a países de honda tradición democrática como

\footnotetext{
80 Marshall, Pablo. Sufragio por Internet: análisis teórico y comparado. Revista Mexicana de Derecho Constitucional Cuestiones Constitucionales, Universidad Nacional Autónoma de México, n. 39, p. 261-293, jul./dic. 2018.

81 Presno, Miguel. Premisas para la introducción del voto electrónico en la legislación electoral española. Revista de Estudios Políticos, Centro de Estudios Politicos y Constitucionales, n. 173, p. 277-304, jul./sep. 2016.

82 Marshall, Pablo. Sufragio por Internet: análisis teórico y comparado. Revista Mexicana de Derecho Constitucional Cuestiones Constitucionales, Universidad Nacional Autónoma de México, n. 39, p. 261-293, jul./dic. 2018.

83 Norris, Pippa. E-Voting as the Magic Ballot. Recuperado el 26 de septiembre de 2020. Disponible en: https://ssrn.com/abstract=336542 or http://dx.doi.org/10.2139/ssrn.336542

84 Toudert, Djamel. Brecha digital, uso frecuente y aprovechamiento de Internet en México. Convergencia Revista de Ciencias Sociales, Universidad Autónoma del Estado de México, n. 79, p. 1-27. enero/abril. 2019.

85 Norris, Pippa. E-Voting as the Magic Ballot. Recuperado el 26 de septiembre de 2020. Disponible en: https://ssrn.com/abstract $=336542$ or http://dx.doi.org/10.2139/ssrn.336542. En el mismo sentido Viollier, Pablo; Riveros, Bastián. Voto electrónico en Chile: una evaluación desde una perspectiva técnica, jurídica y política. Revista Cultura-Hombre-Sociedad, Universidad Católica de Temuco, v. 28, n. 2, p. 12-40, dic. 2018.
} 
los Estados Unidos en Norteamérica; en Europa, puede hablarse de Alemania, Bélgica, Suiza, Países Bajos y Estonia. En Sudamérica, el sufragio electrónico se ha implantado en Argentina, Brasil y Paraguay. Por último, en Asia destaca la experiencia de India.

Por razones de oportunidad y extensión nos limitaremos a analizar aquellos supuestos de implantación considerados consolidados en el tiempo, razonablemente exitosos y tenidos por paradigmáticos cuando se analiza el sufragio electrónico: Brasil y Estonia. Las diferencias entre uno y otro país - de extensión geográfica, pluralidad étnica, desigualdades en el acceso a la tecnología y morfología del Estado - hacen particularmente interesante el contraste analítico. La limitación de los casos estudiados exige prudencia a la hora de realizar conclusiones generalizables.

La experiencia práctica brasileña puede ser considerada un referente a nivel mundial al incluir la totalidad de los procesos electorales (municipales, estatales y nacional) y haber generado beneficios innegables en la participación electoral de grupos sociales tradicionalmente excluidos. Por su parte, las aportaciones de la experiencia estonia con el voto electrónico se vinculan a su condición de pionero en el espacio europeo en el uso de internet como medio de votación y la adopción medidas sugerentes dirigidas al resguardo de las garantías del derecho fundamental de sufragio de sus ciudadanos.

La urna electrónica en Brasil es hoy día un símbolo consolidado en la democracia brasileña. Su origen estuvo motivado por la intención de poner fin al historial de fraudes favorecidos por el sistema de votación anterior y dirigidos por el gobierno militar con la finalidad de asegurarse resultados favorables a sus intereses ${ }^{86}$. La institución diseñada a tal efecto, el Tribunal Superior Electoral de Brasil, sería el órgano encargado de instaurar el sistema de sufragio electrónico y de certificar la legitimidad de los procesos electorales contando para ello con potestades judiciales, legislativas y ejecutivas.

El uso de la tecnología en las elecciones brasileñas se remonta al año 1982, con el país todavía en dictadura y con la finalidad de realizar el recuento de votos en el Estado de Rio de Janeiro. El uso de la tecnología se iría ampliando a otras etapas del proceso hasta implantar las urnas electrónicas en todo el territorio nacional en las elecciones del año $1996^{87}$.

El Tribunal Superior Electoral de Brasil ha implantado continuas mejoras informáticas orientadas a la automatización de las diversas fases que hacen posible el ejercicio del derecho fundamental de sufragio, (v.g, la identificación biométrica de los electores mediante el registro de las huellas dactilares ${ }^{88}$. Este sistema de votación electrónico se caracteriza por ser el resultado de un trabajo de carácter local, interdisciplinario e intergubernamental entre diferentes instituciones del Estado brasileño ${ }^{89}$.

Explicar sucintamente la logística inherente al ejercicio del sufragio electrónico proporcionará un mapa de las ventajas del modelo. El procedimiento de votación electrónico se inicia con el encendido de la urna electrónica y la impresión del número cero como muestra de la inexistencia de votos contabilizados de antemano. El procedimiento continúa con la identificación de los electores según el local de votación, bien mediante la búsqueda del nombre del elector en la lista electrónica o mediante la identificación biométrica en los terminales de las mesas de votación. Realizada la identificación de los electores, el sufragio se emite digitando en un teclado numérico su preferencia y debiendo posteriormente confirmar su elección. Acto

\footnotetext{
86 Talavera, Patricio. Biometría y voto electrónico. Balances y perspectivas a partir de las elecciones de 2014 en Brasil. Ponencia preparada para el CONGRESO NACIONAL DE CIENCIA POLÍTICA,12., organizado por la Sociedad Argentina de Análisis Politico y la Universidad Nacional de Cuyo, Mendoza, p. 1-28. agosto de 2015. Disponible en: https://www.academia.edu/23783556/ Biometr\%C3\%ADa_y_voto_electr\%CC3\%B3nico_Balances_y_perspectivas_a_partir_de_las_elecciones_de_2014_en_Brasil. Acceso: 26 sep. 2019.

87 Brunazo, Amílcar. El voto electrónico en Brasil. En: Tula, María Inés (comp.). Voto Electrónico. Entre votos y máquinas. Las nuevas tecnologías del proceso. Buenos Aires: Ariel, 2005.

88 Padrón, Floralba. E-voting en Colombia: avances y desafíos en la implementación. Revista Derecho del Estado, Universidad de Externado de Colombia, n. 42, p. 211-248, ene./abr. 2019.

89 Tribunal Superior Eleitoral. Segurança do processo eleitoral. Informe explicativo. Disponible en: https://www.justicaeleitoral.jus.br/ spe/. Acceso: 21 sep. 2020
} 
seguido, cada sufragio es encriptado y firmado digitalmente con la finalidad de asegurar su inviolabilidad. Como garantía de inalterabilidad del sufragio emitido, ante cualquier tentativa de modificación la urna electrónica deja de funcionar. Finalmente, los datos encriptados son enviados al centro de escrutinio del Tribunal Regional Electoral, verificándose la autenticidad de la información, la decodificación de los datos y el conteo general de votos del respectivo estado ${ }^{90}$.

Como ya se anticipó anteriormente, la implementación del voto electrónico en Brasil ha sido objeto de interés internacional al haberse verificado ciertas mejoras en el desarrollo del proceso electoral y, por consiguiente, en el ejercicio del derecho fundamental de sufragio. Uno de ellos, imprescindible para la revitalización de las democracias representativas, es el fortalecimiento de los índices de participación ciudadana en las elecciones. El sufragio electrónico garantiza igualmente la universalidad en el ejercicio del sufragio al haberse posibilitado la inclusión de personas que antes de la reforma estaban excluidas por razones sociales y geográficas.

La exclusión de determinados sectores de la población guardaba relación, a su vez, con la compleja orografía de Brasil y, en este punto, ha resultado un éxito el traslado de los dispositivos de votación a dichas localidades. Otro de los grupos tradicionalmente excluidos, las personas analfabetas, han visto facilitada su participación al suministrar la tecnología el reconocimiento de la imagen o símbolo de su candidato. La implantación de ambos factores - el desplazamiento de la logística a los lugares de difícil acceso y el reconocimiento digital de las candidaturas - ha ampliado objetivamente el número de electores en Brasil ${ }^{91}$.

La seguridad e integridad del derecho fundamental de sufragio era otros de los elementos de discusión en el análisis doctrinal precedente. En este punto, el Tribunal Superior Electoral viene afirmando continuadamente la integridad y el carácter secreto de la votación posibilitada por el funcionamiento aislado de las urnas, no conectadas a Internet ni a otras formas de conexión inalámbrica.

La experiencia brasileña podría, a tenor de los hechos aquí puestos de manifiesto, ser catalogada como el paradigma del voto electrónico en Sudamérica. No obstante, este proceso también es susceptible de críticas, como apunta Patricio Talavera. La más evidente, la falta de autocrítica del Tribunal Superior Electoral frente a la existencia de irregularidades en algunos comicios electorales ${ }^{92}$.

Las elecciones presidenciales del año 2000 son una buena muestra de las posibles irregularidades en el desarrollo de los procedimientos electorales electrónicos. En este caso, la autoridad electoral reemplazó los programas homologados por los fiscales de los partidos políticos por versiones no homologadas. Este hecho se ocultó a la ciudadanía y no sería descubierto sino dos años después debido a una pericia realizada en las urnas. Adicionalmente, los dispositivos de votación eran susceptibles de ser abiertos y podían cambiarse los discos de seguridad sin necesidad de romper los sellos de protección de las máquinas de votación ${ }^{93}$. Otros supuestos de irregularidades se detectaron en las elecciones presidenciales del año 2002 en el Estado de Río de Janeiro y Brasilia, en las elecciones a gobernador del año 2006 en Alagoas, en las elecciones municipales del 2008 en Itajaí y las elecciones presidenciales del año $2014^{94}$.

\footnotetext{
90 Tribunal Superior Eleitoral. Segurança do processo eleitoral. Informe explicativo. Disponible en: https://www.justicaeleitoral.jus.br/ spe/. Acceso: 21 sep. 2020

91 Presno, Miguel. Premisas para la introducción del voto electrónico en la legislación electoral española. Revista de Estudios Políticos, Centro de Estudios Politicos y Constitucionales, n. 173, p. 277-304, jul./sep. 2016.

92 Talavera, Patricio. Biometría y voto electrónico. Balances y perspectivas a partir de las elecciones de 2014 en Brasil. Ponencia preparada para el CONGRESO NACIONAL DE CIENCIA POLÍTICA,12., organizado por la Sociedad Argentina de Análisis Politico y la Universidad Nacional de Cuyo, Mendoza, p. 1-28. agosto de 2015. Disponible en: https://www.academia.edu/23783556/ Biometr\%C3\%ADa_y_voto_electr\%CC3\%B3nico_Balances_y_perspectivas_a_partir_de_las_elecciones_de_2014_en_Brasil. Acceso: 26 sep. 2019.

93 Brunazo, Amílcar. El voto electrónico en Brasil. En: Tula, María Inés (comp.). Voto Electrónico. Entre votos y máquinas. Las nuevas tecnologías del proceso. Buenos Aires: Ariel, 2005.

94 Talavera, Patricio. Biometría y voto electrónico. Balances y perspectivas a partir de las elecciones de 2014 en Brasil. Ponencia preparada para el CONGRESO NACIONAL DE CIENCIA POLÍTICA,12., organizado por la Sociedad Argentina de Análisis Politico y la Universidad Nacional de Cuyo, Mendoza, p. 1-28. agosto de 2015. Disponible en: https://www.academia.edu/23783556/
} 
Además de estas irregularidades, diferentes expertos han apuntado brechas en la seguridad de las urnas que, al permitir conocer la identidad y el sentido del sufragio del elector, vulneran la garantía del secreto del sufragio. En este sentido, el Tribunal Superior Electoral convocó en 2009 a la comunidad científica para analizar las debilidades de las urnas electrónicas. En dicho evento se puso de manifiesto que mediante el monitoreo de radiaciones electromagnéticas era posible conocer la opción de votación de cada uno de los electores ${ }^{95}$.

Teniendo en cuenta los pros y contra respecto a la implantación de la urna electrónica, el Tribunal Superior Electoral ha defendido de manera férrea el sufragio electrónico y las garantías que éste ofrece a los procesos electorales en Brasil aminorando las críticas, calificándolas como cuestiones accidentales y anecdóticas producidas por actores ajenos al proceso electoral y atribuyéndoles el objetivo de desinformar y generar incertidumbre en el electorado ${ }^{96}$. Por el contrario, quienes han denunciado las fallas del sistema de votación electrónico brasileño señalan la falta de transparencia en el sistema y la autocomplacencia de las autoridades electorales, factores que acaban comprometiendo la transparencia e integridad del proceso electoral ${ }^{97}$.

La segunda de las experiencias de Derecho comparado en materia de sufragio por internet es, como se anticipó previamente, la desarrollada por Estonia. La república democrática situada en los Balcanes es reconocida internacionalmente por haber desarrollado una cultura de ciberseguridad, uso de internet y redes sociales puntero en el mundo. En este contexto, el e-voto es considerado un servicio público ofrecido y garantizado por el gobierno de turno ${ }^{98}$. Dicho en términos directos: el ejercicio online del derecho de sufragio es uno de los rasgos característicos de las elecciones políticas en Estonia y, en este sentido, es modelo de referencia en la materia.

La experiencia estonia con el e-voto se remonta al año 2005 y la prueba piloto, para los residentes de la capital Tallin, consistió en que pudiesen votar en una encuesta ciudadana. El éxito de la prueba permitió su aplicación en las elecciones municipales del mismo año y, desde esa fecha, su utilización ha ido en aumento hasta las elecciones parlamentarias de marzo de $2020^{99}$.

En la experiencia estonia, el sufragio por internet se entendió como una alternativa viable de votación, confiable para los ciudadanos y que permitiría aumentar los niveles de participación política, especialmente entre los votantes más jóvenes. No obstante, las expectativas teóricas no se han contrastado con datos empíricos que demuestren un aumento significativo en los niveles de participación política ${ }^{100}$. Sí ha existido, por el contrario, un aumento en el número de electores que tradicionalmente habían votado con cédulas de papel y que progresivamente migraron al sufragio por internet. En este sentido, mientras en las elecciones de 2005 tan solo el 1, 85\% de los electores votaron por internet, en las elecciones de 2017 votaron por internet un $32 \%$ de los electores ${ }^{101}$. Esta tendencia alcista alcanzó un máximo histórico del $44 \%$ en las elecciones parlamentarias de marzo de $2020^{102}$.

Biometr\%C3\%ADa_y_voto_electr\%C3\%B3nico_Balances_y_perspectivas_a_partir_de_las_elecciones_de_2014_en_Brasil. Acceso: 26 sep. 2019.

95 Viollier, Pablo; Riveros, Bastián. Voto electrónico en Chile: una evaluación desde una perspectiva técnica, jurídica y política. Revista Cultura-Hombre-Sociedad, Universidad Católica de Temuco, v. 28, n. 2, p. 12-40, dic. 2018.

96 Talavera, Patricio. Biometría y voto electrónico. Balances y perspectivas a partir de las elecciones de 2014 en Brasil. Ponencia preparada para el CONGRESO NACIONAL DE CIENCIA POLÍTICA,12., organizado por la Sociedad Argentina de Análisis Politico y la Universidad Nacional de Cuyo, Mendoza, p. 1-28. agosto de 2015. Disponible en: https://www.academia.edu/23783556/Biometr\%C3\%ADa_y_ voto_electr\%C3\%B3nico_Balances_y_perspectivas_a_partir_de_las_elecciones_de_2014_en_Brasil. Acceso: 26 sep. 2019.

97 Brunazo, Amílcar. El voto electrónico en Brasil. En: Tula, María Inés (comp.). Voto Electrónico. Entre votos y máquinas. Las nuevas tecnologías del proceso. Buenos Aires: Ariel, 2005.

98 Leetaru, Kalev. How Estonia's e-voting system could be the future. Disponible en: https://www.forbes.com/sites $/ \mathrm{kalevleeta-}$ $\mathrm{ru} / 2017 / 06 / 07 /$ how-estonias-e-voting-system-could-be-the-future/\#655741c93b95. Acceso: 21 sep. 2020.

99 Madise, Ülle; Maaten, Epp; Vinkel, Priit. Voto por Internet en Estonia. En: Ayala, Alfonso(coord.). Nuevas avenidas de la democracia contemporánea. México D.F: Universidad Nacional Autónoma de México, 2014. p. 575-601.

100 Madise, Ülle; Maaten, Epp; Vinkel, Priit. Voto por Internet en Estonia. En: Ayala, Alfonso(coord.). Nuevas avenidas de la democracia contemporánea. México D.F: Universidad Nacional Autónoma de México, 2014. p. 575-601.

101 Presno, Miguel. Premisas para la introducción del voto electrónico en la legislación electoral española. Revista de Estudios Políticos, Centro de Estudios Politicos y Constitucionales, n. 173, p. 277-304, jul./sep. 2016.

102 El Nacional. El caso de éxito del voto electrónico en Estonia. ¿Podrá replicarse en Catalunya? Disponible em: https://www.elnacional. cat/es/tecnologia/voto-electronico-estonia-catalunya_363339_102.html. Acceso: 21 de septiembre de 2020. 
El procedimiento de votación por internet se inicia visitando el sitio web de las elecciones. Se requiere como paso previo que el elector se identifique utilizando su tarjeta nacional de identificación electrónica (National ID Cards) y su código PIN. Una vez que ha ingresado en el sistema y ha verificado su identidad, el elector emite su sufragio seleccionando al candidato de su preferencia. Como último paso, debe confirmar su preferencia firmando digitalmente y enviando digitalmente su sufragio. La dinámica del sufragio por internet presenta, en este sentido, ciertas similitudes con otras actividades que se pueden realizar mediante una conexión a la web, como operaciones bancarias o compras ${ }^{103}$.

La salvaguarda de la integridad del proceso electoral por internet es una de las claves de bóveda del sistema. En este sentido, a partir de 2013, el Comité Electoral Nacional de Estonia implementó un proyecto de verificación de votos en virtud del cual los electores tienen la posibilidad de contrastar si su sufragio se recibió en el servidor central. Este doble chequeo requiere que los electores cuenten con teléfonos inteligentes o tablets y una aplicación especial para hacer la lectura de un código QR que aparece en la pantalla del dispositivo al finalizar la votación. La lectura del código QR permite la descarga del sufragio electrónico encriptado, la comprobación del sentido del voto y su recepción por el servidor central ${ }^{104}$.

Es de destacar, dentro de las características del e-voto, el derecho de los electores a modificar el sentido de su voto. Un elector puede, en efecto, modificar ilimitadamente su boleta virtual, contabilizándose como sufragio válido el último emitido o bien aquél que haya sido emitido en papel en una casilla tradicional de votación el día de la elección. Dicho con otras palabras: en caso de existir varios sufragios por internet se considerará válido el último; en caso de existir uno o varios votos electrónicos y uno en cédula de papel se contabilizará este último, declarándose nulos los emitidos previamente por internet. Esta facultad de modificación del sufragio solo puede ser ejercida por los electores durante los días de votación por adelantado, plazo que expira 48 horas antes de la jornada electoral ${ }^{105}$.

El derecho a modificar el sufragio, implementado por el Estado como parte de sus obligaciones de prestación, encuentra su justificación en garantizar dos premisas básicas del contenido esencial del derecho de sufragio: su carácter libre y secreto. De esta forma, se garantiza un ámbito de libertad del elector frente a injerencias injustificadas. Como afirmó la propia Cámara de Revisión Constitucional de Estonia, la posibilidad de modificar el sufragio es un factor no desdeñable de desmotivación para aquellos que ilegítimamente han influido sobre quien ha votado sufriendo coacciones $^{106}$.

De lo hasta aquí expuesto puede deducirse que esta es la historia de un éxito que se ha sostenido en varios pilares interrelacionados: el elevado nivel educativo de la ciudadanía estonia, el alto nivel de penetración de internet, el reducido número de electores, el uso facultativo y no exclusivo del e-voto, su extensión territorial, su clima invernal, etc. Con todo, ha sido la labor decidida del Estado en salvaguardar las garantías mínimas del sufragio el elemento diferencial que ha permitido desarrollar un clima de confianza recíproco entre la población estonia y las instituciones estatales. Un hecho que contrasta, dicho sea de paso, con las fallas experimentadas en el sufragio electrónico en Brasil y que plantearon dudas respecto a la integridad del proceso electoral.

\footnotetext{
103 Vassil, Kristjan; Solvak, Mihkel; Vinkel, Priit; Trechsel, Alexander y Álvarez, Michael. The diffusion of internet voting. Usage patterns of internet voting in Estonia between 2005 and 2015. Government Information Quarterly, 33, p. 453-459, jul. 2016.

104 Madise, Ülle; Maaten, Epp; Vinkel, Priit. Voto por Internet en Estonia. En: Ayala, Alfonso(coord.). Nuevas avenidas de la democracia contemporánea. México D.F: Universidad Nacional Autónoma de México, 2014. p. 575-601.

105 Barrat, Jordi. El secreto del voto en el sufragio por internet. Revista Mexicana de Análisis Político y Administración Pública, Universidad de Guanajuato, v. 1, n. 2, p. 57-71, jul./dic. 2012.

106 Sentencia de la Cámara de Revisión Constitucional de la Suprema Corte de Estonia. Decisión núm. 3-4-1-13-05. Véase en Madise, Ülle; Maaten, Epp; Vinkel, Priit. Voto por Internet en Estonia. En: Ayala, Alfonso(coord.). Nuevas avenidas de la democracia contemporánea. México D.F: Universidad Nacional Autónoma de México, 2014. p. 575-601.
} 


\section{El sufragio electrónico ante las dimensiones subjetiva y objetiva del derecho fundamental de sufragio}

Como se ha tenido ocasión de comprobar, la literatura jurídica y las experiencias comparadas aquí analizadas revelan la existencia de ciertos condicionantes de carácter jurídico, sociales, culturales y técnicos que han de considerarse para la adecuada implementación del sufragio electrónico. Ni que decir tiene que la observancia y cumplimiento de estas condiciones tendrá una influencia innegable en el éxito o fracaso de estos mecanismos de votación. Igualmente, es una obviedad afirmar que el análisis de cada uno de los presupuestos es un trabajo interdisciplinar que excede el objetivo del presente trabajo. Por ello, nos ceñiremos al desarrollo de los presupuestos jurídicos esenciales que han de garantizarse por cualquier sistema de sufragio electrónico.

Como es ampliamente conocido, los principios constitucionales elementales del derecho de sufragio comunes a cualquier Estado democrático reproducen los siguientes caracteres: universal, libre, igualitario, personal y secreto ${ }^{107}$.

Comenzando por el carácter universal del derecho de sufragio, se entiende como: a) la exigencia de incluir al mayor número de personas en el proceso electoral prescindiendo, para ello, de cualquier circunstancia personal, social, cultural, económica, ideológica, política o étnica; b) la exigencia de justificación conforme a principios constitucionales democráticos en casos hipotéticos de exclusión de determinados grupos de personas ${ }^{108}$.

En este sentido, cualquiera sea la noción de la universalidad del sufragio que se adopte se ha de entender como presupuesto de partida para la implementación del sufragio electrónico la garantía de no exclusión de los votantes que tradicionalmente han participado de los procesos electorales; es decir, que quienes son titulares del derecho fundamental de sufragio lo puedan seguir ejerciendo sin ningún tipo de obstáculo ${ }^{109}$. Esta garantía exige que los mecanismos de votación electrónica han de ser comprensibles y de fácil uso para todos los electores, posibilitando a su vez la inclusión de aquellos ciudadanos que por las razones ya indicadas se han visto impedidos de ejercer su derecho de voto. Hablamos, por ejemplo, de las personas discapacitadas, las personas en el extranjero, los analfabetos, etc ${ }^{110}$.

En este punto, y a tenor de las experiencias empíricas analizadas, es posible sostener que el sufragio electrónico asegura el carácter universal. Por una parte, tiene el potencial de facilitar el sufragio y la accesibilidad al mismo en aquellas áreas de difícil acceso, aumentando con ello el universo de electores potenciales y salvaguardando aquellos ya incorporados al circuito electoral ${ }^{111}$. No obstante, y como ya se advirtió, la introducción del sufragio electrónico ha de ser gradual y debe estar acompañada de un proceso educativo dirigido por el Estado y orientado a la totalidad los actores del sistema. Con ello, se evita el efecto adverso de constituirse en una verdadera barrera de entrada para ciertos segmentos del cuerpo electoral. Dicho en términos directos: la accesibilidad universal a los sistemas de votación electrónica y la capacitación del cuerpo electoral son dos requisitos previos a la plena implantación del sufragio electrónico. Mientras tanto, el uso de estos mecanismos debe ser considerado facultativo para los electores y complementario a los sistemas tradicionales de votación en papel ${ }^{112}$.

\footnotetext{
107 Presno, Miguel. Premisas para la introducción del voto electrónico en la legislación electoral española. Revista de Estudios Políticos, Centro de Estudios Políticos y Constitucionales, n. 173, p. 277-304, jul./sep. 2016.

108 Marshall, Pablo. El Derecho de Sufragio. En: Salgado, Constanza; Contreras, Pablo (ed.). Curso de Derechos Fundamentales. Valencia: Tirant lo Blanch, 2020. p. 605-630.

109 Gálvez, Luis; Ruiz, José. El voto electrónico y el test de calidad; o de cuatro bodas complicadas y un posible funeral. Revista de Derecho Politico, Universidad Nacional de Educación a Distancia, n. 81, p. 253-274, mayo/ago. 2011.

110 Comité de Ministros del Consejo de Europa. Recomendación a los Estados miembros sobre los estándares legales, procedimentales y técnicos de los sistemas de votación electrónica. Estrasburgo. 2004. Disponible en: https://www.coe.int/t/dgap/goodgovernance/Activities/KeyTexts/Recommendations/E-votingRec_Spanish.asp. Acceso: 05 mar. 2021.

111 Costa, Joelson. E-voting en Brasil. En: Ayala, Alfonso(coord.). Democracia en la era digital. México: Universidad Nacional Autónoma de México, 2012. p. 119-139.

112 Comité de Ministros del Consejo de Europa. Recomendación a los Estados miembros sobre los estándares legales, procedimentales y técnicos de los sistemas de votación electrónica. Estrasburgo. 2004. Disponible en: https://www.coe.int/t/dgap/goodgovernance/Activities/Key-
} 
La libertad del ejercicio del derecho de sufragio se refiere a la inexistencia de presiones o injerencias externas que restrinjan o limiten la capacidad de decisión de los electores. Esta exigencia, como es fácilmente deducible, está directamente relacionada con la vigencia del principio democrático ${ }^{113}$. En este sentido, el Estado ha de garantizar el establecimiento de condiciones adecuadas para que el elector ejerza su derecho sin coacciones provenientes del exterior.

En este sentido, los sistemas de votación electrónico deben resguardar la libre formación y expresión de la opinión de los electores. Una medida adecuada en este sentido consiste en la posibilidad de modificar el sentido del sufragio y, en los casos más extremos, interrumpir el proceso de votación cuando se vea afectada la libertad de los electores. Por último, la libertad exige que el sistema de sufragio electrónico contemple la posibilidad de votar en blanco o el voto nulo como expresión de protesta frente al funcionamiento del sistema político ${ }^{114}$.

El grado de consecución de esta garantía es desigual en uno y otro modelo de sufragio electrónico. Mientras en el supuesto del voto electrónico presencial no plantea problemas, la situación se reviste de mayor complejidad en el supuesto del sufragio por internet, ya que se ejerce con carácter general en ausencia y sin los controles propios de las autoridades electorales ${ }^{115}$. Esta circunstancia puede generar presiones y amenazas que condicionen su libre ejercicio.

La garantía de la igualdad se refiere a que a cada ciudadano le corresponda igual cantidad de votos en las elecciones y cada uno de esos votos se cuente por igual. Dicho en otros términos: esta garantía exige la obligación de atribuir el mismo valor a todos los sufragios emitidos como forma de garantizar el pluralismo y la igualdad política. A sensu contrario, queda excluida la posibilidad de establecer sistemas de sufragio plural en que se le reconozca un mayor valor al sufragio de cualquier ciudadano sobre otro o la posibilidad de que un ciudadano pueda votar más de una vez en la misma elección ${ }^{116}$.

Esta garantía exige un alto estándar de cumplimiento a los sistemas de votación electrónicos. En primer lugar, se deben evitar errores de escrutinio e intentos de fraudes electorales ${ }^{117}$. Asimismo, las medidas adoptadas por la autoridad electoral deben ser compatibles con la libertad de voto. En este punto, como se ha visto en el caso estonio, resulta de especial utilidad la posibilidad de modificar ilimitadamente el sufragio durante un lapso de tiempo. Las autoridades, por su parte, deben garantizar que el sufragio sea contabilizado una sola vez con independencia del número de veces que haya sido modificado. En aquellos casos que existan sistemas de votación mixtos, el órgano electoral debe asegurar que solo se contabilizará un voto por elector, no siendo relevante el sistema utilizado para ello.

El sufragio por internet genera dudas legítimas respecto a la igualdad del voto. No resulta arriesgado afirmar la existencia, en líneas generales, de brechas digitales que afectan con especial incidencia a las personas de menores ingresos y mayor edad. Esta realidad coloca en tela de juicio el resguardo de la igualdad de voto en la modalidad de «sufragio en ausencia». Sin perjuicio de lo anterior, el sufragio por internet tiene a su vez el potencial de resolver unos de los aspectos más delicados de la igualdad de voto: el valor que se le reconoce a cada sufragio dependiendo de la circunscripción y del número de cargos que se elijan en cada una de ellas. En este sentido, su implementación supondría redefinir el concepto de circunscripción y territorialidad con la finalidad de establecer criterios que permitan garantizar la igualdad del valor.

\footnotetext{
Texts/Recommendations/E-votingRec_Spanish.asp. Acceso: 05 mar. 2021.

113 Presno, Miguel. Premisas para la introducción del voto electrónico en la legislación electoral española. Revista de Estudios Políticos, Centro de Estudios Politicos y Constitucionales, n. 173, p. 277-304, jul./sep. 2016.

114 Marshall, Pablo. Sufragio por Internet: análisis teórico y comparado. Revista Mexicana de Derecho Constitucional Cuestiones Constitucionales, Universidad Nacional Autónoma de México, n. 39, p. 261-293, jul./dic. 2018.

115 Gálvez, Luis; Ruiz, José. El voto electrónico y el test de calidad; o de cuatro bodas complicadas y un posible funeral. Revista de Derecho Politico, Universidad Nacional de Educación a Distancia, n. 81, p. 253-274, mayo/ago. 2011.

116 Marshall, Pablo. El Derecho de Sufragio. En: Salgado, Constanza; Contreras, Pablo (ed.). Curso de Derechos Fundamentales. Valencia: Tirant lo Blanch, 2020. p. 605-630.

117 Gálvez, Luis; Ruiz, José. El voto electrónico y el test de calidad; o de cuatro bodas complicadas y un posible funeral. Revista de Derecho Politico, Universidad Nacional de Educación a Distancia, n. 81, p. 253-274, mayo/ago. 2011.
} 
La garantía de sufragio personal parte de una afirmación básica: no se debe confundir el carácter personal del sufragio con su presencialidad forzosa. El carácter personal del voto supone que debe ser ejercido de manera exclusiva por su titular. Quedan excluidas la sustitución y delegación del voto por terceros ${ }^{118}$. Por su parte, la presencialidad exige la comparecencia del votante al acto electoral.

Los sistemas de votación electrónico presencial no presentan mayores inconvenientes para asegurar la personalidad del voto al existir mecanismos que permiten una adecuada identificación de los electores. En este punto, la experiencia empírica brasileña provee mecanismos satisfactorios como los sistemas de identificación dactilar y la biométrica que, por su idoneidad, han sido incorporados dicho sea de paso al sistema electoral colombiano ${ }^{119}$. Los problemas, nuevamente, surgen con el sufragio por internet. En este modelo, la votación se realiza en un entorno no controlado por la autoridad electoral y, en consecuencia, no existe la certeza absoluta sobre la identidad real de quien ha emitido el sufragio sea realmente al elector, pudiendo producirse la suplantación del mismo ${ }^{120}$. Si bien la personalidad no es idéntica a la presencialidad, no es menos cierto que son elementos que se encuentran asociados. La presencialidad, no es vano recordarlo, está condicionada al control inmediato y directo de las autoridades electorales que, resta decirlo, reduce las posibilidades de suplantar a uno o varios electores.

El secreto del sufragio surge como una forma de asegurar la libertad del voto y se relaciona con una concepción no deliberativa del sistema democrático, según la cual el elector es un elemento esencial de la comunidad política y dotado de la capacidad para decidir en soledad el destino del colectivo ${ }^{121}$. El contenido del secreto de voto implica que la preferencia del elector no puede ser conocida por una persona diferente de sí mismo, a menos que concurra su propio consentimiento ${ }^{122}$.

Si para los sistemas tradicionales de votación resulta difícil asegurar el secreto del voto, esta exigencia se agrava en los sistemas de votación electrónicos, en los cuales no existe un respaldo físico de los votos emitidos por los electores. Con la finalidad de superar esta contrariedad, se ha planteado que los sistemas de votación electrónica sean diseñados para salvaguardar el anonimato del votante desde el momento de la autentificación hasta el momento del escrutinio, no dando espacio a la posibilidad de reconstruir el vínculo entre el votante y su voto ${ }^{123}$.

Del análisis aquí realizado se pueden extraer algunas conclusiones parciales que conviene señalar. La primera - con las limitaciones propias del universo comparado analizado - es que a día de hoy los sistemas de votación electrónico no son completamente seguros al existir la probabilidad de sufrir ataques procedentes de terceros ajenos al proceso electoral. En el caso del voto electrónico presencial, las incertidumbres incluyen brechas de seguridad en el hermetismo de los dispositivos de votación - como se ha visto en el caso brasileño - o la decodificación de las emisiones electromagnéticas de las máquinas que hacen factible conocer el contenido de los votos y la identidad de los electores.

Esta incertidumbre se hace aún más evidente en el caso del e-voto ante la inexistencia de los controles que existen en los locales de votación. Además, esta modalidad lleva aparejada el riesgo de privatizar las elec-

\footnotetext{
118 Marshall, Pablo. El Derecho de Sufragio. En: Salgado, Constanza; Contreras, Pablo (ed.). Curso de Derechos Fundamentales. Valencia: Tirant lo Blanch, 2020. p. 605-630.

119 Padrón, Floralba. E-voting en Colombia: avances y desafíos en la implementación. Revista Derecho del Estado, Universidad de Externado de Colombia, n. 42, p. 211-248, ene./abr. 2019.

120 Gálvez, Luis; Ruiz, José. El voto electrónico y el test de calidad; o de cuatro bodas complicadas y un posible funeral. Revista de Derecho Politico, Universidad Nacional de Educación a Distancia, n. 81, p. 253-274, mayo/ago. 2011.

121 Barrat, Jordi. El secreto del voto en el sufragio por internet. Revista Mexicana de Análisis Político y Administración Pública, Universidad de Guanajuato, v. 1, n. 2, p. 57-71, jul./dic. 2012.

122 Marshall, Pablo. El Derecho de Sufragio. En: Salgado, Constanza; Contreras, Pablo (eds.). Curso de Derechos Fundamentales. Valencia: Tirant lo Blanch, 2020. p. 605-630.

123 Comité de Ministros del Consejo de Europa. Recomendación a los Estados miembros sobre los estándares legales, procedimentales y técnicos de los sistemas de votación electrónica. Estrasburgo. 2004. Disponible en: https://www.coe.int/t/dgap/ goodgovernance/Activities/Key-Texts/Recommendations/E-votingRec_Spanish.asp. Acceso: 05 mar. 2021.
} 
ciones $^{124}$. Ha de recordarse que el acto de votar se realiza mediante dispositivos personales de los electores y, en consecuencia, resulta mucho más fácil vulnerar la reserva del sufragio.

Más allá de las modalidades de introducir brechas de seguridad y confidencialidad que se han puesto de manifiesto en los procesos de sufragio electrónico, hay otra incertidumbre que apuntar: en última instancia, puede bastar con interceptar la información contenida en los servidores de almacenamiento de datos para saber cómo votó cada persona. Esta es una posibilidad que no se da en la modalidad tradicional de sufragio mediante papeleta electoral; en efecto, una vez depositado el voto en la urna, este se entremezcla con los demás y hace imposible vincularlo con algún elector en particular ${ }^{125}$.

\section{Conclusiones}

Las restricciones de movilidad y la crisis sanitaria provocada por la COVID-19 ha motivado la reactivación de la discusión política y académica sobre la conveniencia de implantar sistemas de votación alternativos al sufragio tradicional. La variable considerada se refiere, como es fácilmente deducible, a la implantación del sufragio electrónico - presencial o por internet - en los procesos electorales.

Las ventajas asociadas a su establecimiento han sido puestas de manifiesto mediante el estudio del estado del arte doctrinal y el recurso - parcial por cuestiones de oportunidad - a la praxis de Derecho comparado brasileño y estonio. Debe decirse que los beneficios no son en modo alguno desdeñables. El sufragio electrónico es un sistema muy célere, ágil y medioambientalmente sostenible. No puede decirse lo mismo en relación a su idoneidad para paliar una variable endémica de los sistemas democráticos actuales: las tasas de abstención electoral que se expresan con especial intensidad entre los más jóvenes. Esta característica del sistema ha sido reconocida por la doctrina especializada como fatiga democrática y/o desafección política. En este contexto, las severas restricciones de la movilidad e incremento de las dificultades logísticas derivadas de la crisis de salud pública provocada por la COVID-19 solo arrojan una mayor incertidumbre a este contexto.

Continuando con este punto, no parece existir una posición doctrinal mayoritaria ni suficiente información empírica sobre los beneficios - en términos de aumento considerable de la participación electoral - que conllevaría la implantación generalizada del sistema de sufragio electrónico. Se intuye, por el contrario, cierto aire de voluntarismo por parte de algunos sectores tecnófilos cuya euforia por las propiedades terapéuticas de la democracia digital convendría rebajar.

Otra de las ventajas que promueve el sufragio electrónico es el potencial inclusivo de grupos sociales tradicionalmente excluidos del proceso electoral. Este beneficio traería consigo, a su vez, un fortalecimiento de las habilidades informáticas de tales sectores y la construcción, por extensión, de nuevos espacios de deliberación democrática entre diversos sectores de la sociedad.

En este punto, debe realizarse una matización: las ventajas aquí puestas de manifiesto están analizadas principalmente en el plano doctrinal y deben, en consecuencia, relativizarse ante la falta de un análisis empírico más solvente. Los modelos brasileño y estonio nos han proporcionado datos parciales que permiten realizar conjeturas mínimamente fundamentadas, pero no concluyentes. La deseable completud del análisis requiere tener en cuenta otras variables extrajurídicas, cuyo análisis excede completamente el modesto objetivo de este trabajo y que también inciden en la posible incorporación del sistema electrónico de votación: el grado de madurez democrática de los operadores políticos, la mayor o menor cultura de participación electoral, los incentivos a la participación de los jóvenes y su afiliación a partidos, la distribución geográfica

124 GONZÁLEZ, Luis. Voto electrónico por internet y riesgos para la democracia (I). Revista Derecho Político, Universidad Nacional de Educación a Distancia, n. 74, p. 163-209, ene./abr. 2009.

125 Barrat, Jordi. El secreto del voto en el sufragio por internet. Revista Mexicana de Análisis Político y Administración Pública, Universidad de Guanajuato, v. 1, n. 2, p. 57-71, jul./dic. 2012. 
y territorial del país, la brecha digital, el pluralismo étnico, etc...

La principal incertidumbre de la introducción generalizada del sistema de sufragio electrónico es aquella que guarda relación con la salvaguarda de tres principios constitucionales esenciales del derecho de sufragio y cuya vulneración desnaturalizaría su esencia: su carácter secreto, libre e igualitario. En este sentido, tan solo la universalidad no plantea problema a tenor de los argumentos aquí presentados a favor del potencial inclusivo de los grupos sociales tradicionalmente excluidos. Tampoco afecta a la exclusión de aquellos grupos normalmente incluidos en el proceso electoral. No son pocos, sin embargo, los medios y métodos informáticos analizados a través de los cuales se puede poner en entredicho la imprescindible libertad, igualdad y carácter secreto del voto. No hay como negar, en consecuencia, que el voto tradicional mediante el depósito de papeleta en urna presenta mayores certidumbres en el mantenimiento de tales garantías.

De los pros y contras aquí evaluados puede concluirse que es necesario repensar la conveniencia de sustituir el modelo tradicional de votación por el sufragio electrónico. Su implantación progresiva al estilo de Estonia parece una medida prudente, con las limitaciones ya anteriormente apuntadas. Por el contrario, las ventajas no parecen ser tan relevantes como las incertidumbres relativas a la salvaguarda de las características configuradoras del derecho de sufragio ya advertidas. Su posible vulneración, prácticamente descartadas en el modelo tradicional, acabaría desnaturalizando el derecho de sufragio y, paralelamente, generaría mayores problemas en el funcionamiento y legitimidad del sistema democrático de los que a día de hoy parece poder resolver.

\section{Referencias}

Aguirre, Jorge. Aportes de la web a la participación ciudadana y la representatividad democrática. Revista Chilena de Derecho y Tecnología, Centro de Estudios en Derecho Informático de la Universidad de Chile, v. 4, n. 1, p. 145186, primer semestre, 2015.

Aleuy, Mahmud. La votación electrónica. Em: Fontaine, Arturo; Larroulet, Cristián; VIERA-GALLO, José; WALKER, Ignacio (ed.). Modernización del Régimen Electoral Chileno. Santiago de Chile-CIEPLAN, 2007. p. 221-240. Disponible en http://www.cieplan.org/media/publicaciones/archivos/112/Capitulo_2.pdf. Acceso: 05 mar. 2021.

ARAGÓN, Manuel. Derecho de sufragio: principio y función. En: NOHLEN, Dieter; ZOVATTO, Daniel; OROZCO, Jesús; THOMPSON, José (comp.). Tratado de Derecho Electoral comparado de América Latina. 2. ed. México: FCE, Instituto Interamericano de Derechos Humanos, Universidad de Heidelberg, International IDEA, Tribunal Electoral del Poder Judicial de la Federación, Instituto Federal Electoral, 2007.

Barrat, Jordi. El secreto del voto en el sufragio por internet. Revista Mexicana de Análisis Político y Administración Pública, Universidad de Guanajuato, v. 1, n. 2, p. 57-71. Jul./dic. 2012.

Barrat, Jordi. Observación electoral y voto electrónico. Revista Catalana de Dret Públic, Generalitat de Catalunya: Escola d'Administració Pública de Catalunya, n. 39, p. 277-296, dic. 2009.

Barrientos, Fernando. Dimensiones discursivas en torno al voto electrónico. Revista de Ciencia Política, Pontifica Universidad Católica de Chile, v. 27, n. 1, p. 111-131, 2007.

Bastida, Francisco. Elecciones y Estado democrático de Derecho. Revista Española de Derecho Constitucional, n. 32, p. 115-134, 1991.

Bobbio, Norberto. El Futuro de la Democracia. Traducción de Fernández, José. México DF: Fondo de Cultura Económica de México, 1986. 
Brunazo, Amílcar. El voto electrónico en Brasil. En: Tula, María Inés (comp.). Voto Electrónico. Entre votos y máquinas. Las nuevas tecnologías del proceso. Buenos Aires: Ariel, 2005.

CARRO, Antonio. Derecho Político. Madrid: Editorial Universidad de Madrid, 1959.

CHUAQUI, Tomás. Participación Electoral Obligatoria: Una Defensa. Em: Fontaine, Arturo; Larroulet, Cristián; VIERA-GALLO, José; WALKER, Ignacio (ed.). Modernización del Régimen Electoral Chileno. Santiago de Chile-CIEPLAN, 2007, p. 183-203. Disponible en https://www.cieplan.org/wp-content/uploads/2019/12/Modernizacion-del-regimen-electoral-chileno.pdf. Acceso: 05 mar. 2021.

Comité de Ministros del Consejo de Europa. Recomendación a los Estados miembros sobre los estándares legales, procedimentales y técnicos de los sistemas de votación electrónica. Estrasburgo. 2004. Disponible en: https://www.coe. int/t/dgap/goodgovernance/Activities/Key-Texts/Recommendations/E-votingRec_Spanish.asp. Acceso: 05 mar. 2021.

Costa, Joelson. E-voting en Brasil. En: Ayala, Alfonso(coord.). Democracia en la era digital. México: Universidad Nacional Autónoma de México, 2012.

DUGUIT, León. Manual de Derecho Constitucional. Madrid: Librería F. Beltrán, 1926. Traducción, prólogo y apéndice de ACUÑA, José.

El Nacional. El caso de éxito del voto electrónico en Estonia. ¿Podrá replicarse en Catalunya? Disponible en https://www.elnacional.cat/es/tecnologia/voto-electronico-estonia-catalunya_363339_102.html. Acceso: 21 sep. 2020.

Fernández, Rosa. El voto electrónico: El caso vasco. Revista de Estudios Políticos, Centro de Estudios Políticos y Constitucionales, n. 112, p. 199-236, abr./jun. 2001.

FERRAJOLI, Luigi. Los Fundamentos de los Derechos Fundamentales. Traducción de DE CABO, Antonio y PISARELLO, Gerardo. Madrid: Trotta, 2001.

GÁLVEZ, Luis. El Derecho de Sufragio en el Siglo XX. En Derechos y Libertades de la Universidad Carlos III de Madrid, n. 31, p. 163-189, jun. 2014.

Gálvez, Luis; Ruiz, José. El voto electrónico y el test de calidad; o de cuatro bodas complicadas y un posible funeral. Revista de Derecho Politico, Universidad Nacional de Educación a Distancia, n. 81, p. 253-274, mayo/ago. 2011.

García, María. Elementos de Derecho Electoral. Valencia: Tirant lo Blanch, 2010.

González, José; del Nogal, José; Müller, Roger. Venezuela: El voto electrónico. Auditorias y legitimidad del sistema automatizado de votación. Revista Espacio Abierto, Universidad del Zulia, v. 21, n. 2, p. 305-321, abr./ jun. 2012.

González, Luis. Voto electrónico por internet y riesgos para la democracia (I). Revista de Derecho Político, Universidad Nacional de Educación a Distancia, n. 74, p.163-209, ene./abr. 2009.

González, Luis. Voto electrónico por internet y riesgos para la democracia (II). Revista Derecho Político, Universidad Nacional de Educación a Distancia, n. 77, p.213-249, ene./abr. 2010.

HERRERA, Edgard; VILLALOBOS, Enrique. Sufragio y Principio democrático: Consideraciones sobre su existencia y vinculancia. Revista de Derecho Electoral, n. 1, p. 89-108, primer semestre 2006.

Kelsen, Hans. Compendio de Teoría general del Estado. [S.l.]: Colofón, 1992. Traducción de Recaséns, Luis y de Ascárte, Justino.

Leetaru, Kalev. How Estonia's e-voting system could be the future. Disponible en: https://www.forbes.com/sites/ kalevleetaru/2017/06/07/how-estonias-e-voting-system-could-be-the-future/\#655741c93b95. Acceso: 21 sep. 2020. 
López, José; de Santiago, Monserrat. Significado y función del derecho de sufragio en la actividad electoral de un Estado democrático. Revista Novum Jus, v. 12, n. 1, p. 59-82. ene./jun. 2018.

Madise, Ülle; Maaten, Epp; Vinkel, Priit. Voto por Internet en Estonia. En: Ayala, Alfonso(coord.). Nuevas avenidas de la democracia contemporánea. México D.F: Universidad Nacional Autónoma de México, 2014.

Marshall, Pablo. El derecho a votar desde el extranjero. Revista de Derecho, Valdivia, v. XXIV, n. 2, p. 139-161, dic. 2011.

Marshall, Pablo. El Derecho de Sufragio. En: Salgado, Constanza; Contreras, Pablo (ed.). Curso de Derechos Fundamentales. Valencia: Tirant lo Blanch, 2020.

MARSHALL, Pablo. El derecho y la obligación de votar. Revista de Derecho, Valdivia, v. XXII, p. 77-91, jul. 2009.

Marshall, Pablo. Elecciones representativas y legitimidad democrática: una mirada desde las concepciones normativas de la democracia. Revista de Derecho, Valdivia, v. XXX, n. 2, p. 275-299, dic. 2017.

Marshall, Pablo. Sufragio por Internet: análisis teórico y comparado. Revista Mexicana de Derecho Constitucional Cuestiones Constitucionales, Universidad Nacional Autónoma de México, n. 39, p. 261-293. jul./dic. 2018.

Norris, Pippa. E-Voting as the Magic Ballot. Recuperado el 26 de septiembre de 2020. Disponible en: https:// ssrn.com/abstract=336542 or http://dx.doi.org/10.2139/ssrn.336542.

Padrón, Floralba. E-voting en Colombia: avances y desafíos en la implementación. Revista Derecho del Estado, Universidad de Externado de Colombia, n. 42, p. 211-248, ene./abr. 2019.

PAREDES, Felipe. Teoría Constitucional y Bases de la Institucionalidad. Valencia: Tirant lo Blanch, 2020.

PRESNO, Miguel. El derecho de voto como derecho fundamental. Revista Mexicana de Derecho Electoral, n. 2, p. 109-151, jul./dic. 2012.

Presno, Miguel. El Derecho de Voto. Madrid: Tecnos, 2003.

Presno, Miguel. Premisas para la introducción del voto electrónico en la legislación electoral española. Revista de Estudios Políticos, Centro de Estudios Políticos y Constitucionales, n. 173, p. 277-304, jul./sep. 2016.

Richey, Sean. Who Votes Alone? The Impact of Voting by Mail on Political Discussion. Australian Journal of Political Science, v. 40, n. 3, p. 435-442. Sep. 2005.

Sebastián, Luis. Reflexiones sobre democracia y representación. El sistema electoral valenciano. En: Nicasio, Blanca; Pérez, Marta (ed.). Defender la Democracia. Estudios sobre la calidad democrática, buen gobierno y lucha contra la corrupción. Valencia: Tirant lo Blanch, 2020.

Sierra, Lucas. El Voto como Derecho: Una Cuestión de Principios. Em: Fontaine, Arturo; Larroulet, Cristián; Viera-Gallo, José; Walker, Ignacio (ed.). Modernización del Régimen Electoral Chileno. Santiago de Chile-CIEPLAN, 2007. p. 157-181. Disponible em: https://www.cieplan.org/wp-content/uploads/2019/12/ Modernizacion-del-regimen-electoral-chileno.pdf. Acceso: 05 marzo 2021.

Sieyes, Emmanuel. ¿Qué es el tercer Estado? [S.1.]: Omegalfa, 2019. Traducción en Clásicos de Historia.

SolozábAL, Juan. La actuación efectiva del proceso electoral y sus posibilidades. Revista Española de Derecho Constitucional, n. 70, p. 127-160, 2004.

Solozábal, Juan. Una revisión de la teoría de los derechos fundamentales. Revista Jurídica Universidad Autónoma de Madrid, n. 4, 25 ago. 2016.

SOTO, Francisco. Reflexiones sobre el voto obligatorio. Revista de Derecho Público de la Universidad de Chile, p. 339-351, 2018. 
Talavera, Patricio. Biometría y voto electrónico. Balances y perspectivas a partir de las elecciones de 2014 en Brasil. Ponencia preparada para el CONGRESO NACIONAL DE CIENCIA POLÍTICA,12., organizado por la Sociedad Argentina de Análisis Político y la Universidad Nacional de Cuyo, Mendoza, p. 1-28. agosto de 2015. Disponible en: https://www.academia.edu/23783556/Biometr\%C3\%ADa_y_voto_electr\%C3\%B3nico_ Balances_y_perspectivas_a_partir_de_las_elecciones_de_2014_en_Brasil. Acceso: 26 sep. 2019.

Téllez, Julio. El Voto Electrónico. Coyoacán: Tribunal Electoral del Poder Judicial de la Federación, 2010.

Tokaji, Daniel. The Paperless Chase: Electronic Voting and Democratic Values. En Public Law and Legal Theory Working Paper, Ohio State University Moritz College of Law. Series n. 25, p. 1-95, dic. 2004.

Toudert, Djamel. Brecha digital, uso frecuente y aprovechamiento de Internet en México. Convergencia Revista de Ciencias Sociales, Universidad Autónoma del Estado de México, n. 79, p. 1-27, ene./abr. 2019.

Tribunal Superior Eleitoral. Segurança do processo eleitoral. Informe explicativo. Disponible en: https://www. justicaeleitoral.jus.br/spe/. Acceso: 21 sep. 2020.

Tula, María Inés. Democracia, elecciones y nuevas tecnologías. El voto electrónico. Revista Mexicana de Análisis Político y Administración Pública, Universidad de Guanajuato, v. 1, n. 2, p. 9-21. jul./dic. 2012.

URBINA, Francisco. Derecho de Sufragio: La debatida cuestión de su obligatoriedad. Estudios Constitucionales, v. 7, n. 1, p. 361-384, 2009.

Vassil, Kristjan; Solvak, Mihkel; Vinkel, Priit; Trechsel, Alexander; Álvarez, Michael. The diffusion of internet voting. Usage patterns of internet voting in Estonia between 2005 and 2015. Government Information Quarterly, 33, p. 453-459, Jul. 2016.

Viollier, Pablo; Riveros, Bastián. Voto electrónico en Chile: una evaluación desde una perspectiva técnica, jurídica y política. Revista Cultura-Hombre-Sociedad, Universidad Católica de Temuco, v. 28, n. 2, p. 12-40. dic. 2018. 
Para publicar na revista Brasileira de Políticas Públicas, acesse o endereço eletrônico www.rbpp.uniceub.br

Observe as normas de publicação, para facilitar e agilizar o trabalho de edição. 